\title{
Farm Rejuvenation-Induced Changes in Tree Spatial Pattern and Live Biomass Species of Cocoa Agroforests in Central Cameroon: Insights for Tree Conservation Incentives in Cocoa Landscapes
}

\author{
Frederick N. Numbisi ${ }^{1,2, *,+} \mathbb{D}$, Dieudonne Alemagi ${ }^{2, \ddagger}$, Ann Degrande $^{2} \mathbb{D}$ and Frieke Van Coillie ${ }^{1}$ (D) \\ 1 Remote Sensing I Spatial Analysis Lab (REMOSA), Department of Environment, Faculty of \\ Bioscience Engineering, Ghent University, Coupure Links 653, 9000 Gent, Belgium; \\ Frieke.Vancoillie@UGent.be \\ 2 World Agroforestry (ICRAF), West and Central Africa Regional Office, Yaoundé P. O. Box 16317, Cameroon; \\ dalemagi@yahoo.co.uk (D.A.); A.Degrande@cgiar.org (A.D.) \\ * Correspondence: frederick.n.numbisi@gmail.com; Tel.:+49-178-310-7190 \\ + Current address: Independent Researcher, Freiburg im Breisgau, 79424 Auggen, Germany; \\ Tel.: +49-7631-9311118. \\ ‡ Current address: FOKABS Inc. 955 Rotary Way, Ottawa, ON K1T 0L2, Canada; Tel.: +1-613-261-3299.
}

Citation: Numbisi, F.N.; Alemagi, D.; Degrande A.; Van Coillie, F. Farm Rejuvenation-Induced Changes in Tree Spatial Pattern and Live Biomass Species of Cocoa Agroforests in Central Cameroon: Insights for Tree Conservation Incentives in Cocoa Landscapes. Sustainability 2021, 13, 8483. https://doi.org/10.3390/ su13158483

Academic Editors: Bhim Bahadur Ghaley and Andrea Pisanelli

Received: 19 June 2021

Accepted: 23 July 2021

Published: 29 July 2021

Publisher's Note: MDPI stays neutral with regard to jurisdictional claims in published maps and institutional affiliations.

Copyright: (c) 2021 by the authors Licensee MDPI, Basel, Switzerland. This article is an open access article distributed under the terms and conditions of the Creative Commons Attribution (CC BY) license (https:// creativecommons.org/licenses/by/ $4.0 /)$.
Abstract: Cocoa agroforests sustain ecosystem services (ESs) to varying degrees. These services are otherwise mostly provided by other non-cocoa shade or companion trees. However, the density of shade trees is associated with services and/or disservices that drive farm-specific tree management successions. Considering the growing impacts of climate crisis on farm productivity and the need for adaptation strategies, the ESs are increasingly provisional and contingent on the prevailing vegetation, land tenure, and management successions, amongst others social and ecological factors. To assess the temporal changes in shade management, we surveyed an age gradient of "family farms" in cocoa agroforests created from forest (fCAFS) and savannah (sCAFS) land cover. We evaluated the temporal changes in farm structure, relative tree abundance, and live aboveground biomass of the major canopy strata. We used a spatial point process and linear mixed effect analysis to assess the contributions of associated perennial trees (AsT) on farm rejuvenation patterns. The density of cocoa trees was inconsistent with farm age; this was significantly high on farms in sCAFS (1544 trees ha ${ }^{-1}$ ) with spatially random configuration across farm age. On farms in fCAFS, we observed a transition of the cocoa tree configuration in the order regular, random, and clustering from young (with highest density of 1114 trees $\mathrm{ha}^{-1}$ ) to old farms. On a temporal scale, there is no clear distinction of farm structure and biomass between fCAFS and sCAFS. However, the cycle of tree species and structural composition of the canopy strata are dissimilar; the live biomass allocation for the considered use groups of tree species was different with farm age. The observed dynamics in canopy tree structure and live biomass provide insights into farmers' temporal allocation of uses and prioritization of different tree species with farm age. We recommend the consideration of such landscape-specific, tree management dynamics in proposing on-farm tree conservation incentives. Our results are also conducive to reliable estimates of the ecosystem services from CAFS in the national implementation of conservation mechanisms such as REDD ${ }^{+}$.

Keywords: cocoa agroforests; canopy tree diversity; farm adaptation; farm rejuvenation; tree configuration; spatial point pattern; $\mathrm{REDD}^{+}$; ecosystem services

\section{Introduction}

The nature and magnitude of ecosystem services (ESs) of a cocoa agroforestry system (CAFS) inevitably change across farm age and management cycles. In the literature, a CAFS is described as ccoa production under a multi-strata canopy or shade from diverse tree 
species. Such production systems are considered more ecologically sustainable and likened to transition forests in terms of the potential to sustain ecosystem services such as carbon sequestration, habitat (corridor) provision, and biodiversity conservation [1-5]. The negative impacts of climate change (CC) on full-sun cocoa have been widely reported. Thus, the provided ESs in CAFSs may depend largely on the type and density of associated non-cocoa or shade trees of interest to farmers [6]. Besides other factors such as land tenure, CC is increasingly imparting landscape- and farm-specific challenges regarding tree management and the perceived services it provides. Thus, it is unrealistic to assume a permanence of services in CAFS establishment (or time of assessment) in projecting the ecological potentials of such systems. An understanding of the underlying trade-offs between farmers' (or farm managers) practices and the type, density, and distribution of associated tree species is thus required on a temporal basis. This may inform about sustainable landscape management strategies, land use contributions to biodiversity conservation mechanisms such as REDD ${ }^{+}$ (reducing emissions from deforestation and forest degradation and the role of conservation, sustainable management of forests, and enhancement of forest carbon stocks in developing countries), and ecosystem restoration planning.

In food and tree crop production landscapes across the globe, land use managers are faced with challenges to simultaneously address the trilemma of negative impacts of climate crisis, increasing loss of biodiversity, and unsustainable crop production systems. An increasing area of tropical forest is lost annually through the progressive conversion into cocoa farms featuring varying or no shade [7,8]. From a global assessment, Ordway et al. [9] observed that cocoa was responsible for $57 \%$ of the global agricultural land expansion

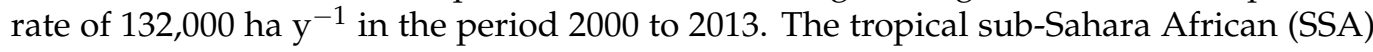
region harbors the world's main cocoa exporting countries (Ivory Coast, Ghana, Cameroon, and Nigeria), which jointly contribute up to $70 \%$ of global cocoa dry bean production [10]. The major production is from full-sun or unshaded cocoa plantations in Ivory Coast and Ghana. However, cocoa plantation expansion strategies, whether full sun or shaded cocoa, are country- and site-specific [11-14]. Thus, a consolidated information local (on-farm) tree management in CAFSs may provide insights about the dynamics in landscape adaptation practices. Such farm dynamics are vital to inform about and customize effective national (if not landscape) management incentives for tree species conservation and sustaining ecosystem integrity.

Of the countries in the Congo Basin, Cameroon takes the lead in cocoa production, and the establishment of CAFSs is mainly through forest conversion by selective thinning or clear-felling [15]. These are mostly complex CAFSs of varying multi-strata canopy structure [16]. As in other major cocoa-producing countries in the region, cocoa agroforestry extensions occur mostly on small-holder family farms, usually 1-2 ha, along the nexus of remaining forests $[8,16]$. Additionally, in general, the trees associated with cocoa in CAFSs are prioritized by farmers for several uses, often multi-purpose: as a source of timber, as provision of fruits and other non-timber forest products (NTFPs), and as shade provision to young cocoa plants [17]. While agronomic techniques recommend cocoa cultivation under $40-50 \%$ shade level [18], farm practice differs from this. Shade tree retention or planting in cocoa agroforests is more often practised by farmers who are more aware of the multiple uses of indigenous trees compared with migrant farmers [19]. Cocoa farmers who practise agroforestry have developed strategies to introduce multi-purpose fruit tree species to supplement income sources [20]. In the Centre Region of Cameroon, farmers have developed innovative practices by creating CAFS on savannah landscapes. Compared with plantations created from forest cover (hereafter, fCAFS), these savannah cocoa agroforests (hereafter sCAFS) feature a different successional phase of shade tree management [11].

Shade tree management in CAFSs has been widely studied in relation to biodiversity conservation, pest and disease control, canopy structure, and carbon stock $[1,14,21-23]$. However, few studies have evaluated the horizontal structural dynamics in and shade tree management strategies across a scale of farm age. The concept of stand basal area, 
a measure of relative dominance, has been used in forestry research to measure tree succession and stand productivity but far less so in agroforestry management. In agroforestry, other management measures, such as farm certification, have been suggested to incentivize shade tree planting by cocoa farmers $[13,20]$. To promote shaded cocoa production and ecological services from associated shade trees, Farm Certification Standards use tree density as a proxy for managing the shade level in farms. For instance, the Rainforest Alliance (RA) in Ghana recommends $40 \%$ shade cover that should be provided by at least 12 (of 19 selected) native tree species per hectare, and the tree canopy should comprise at least two strata [24]. However, based on tree diameter and crown area, shade provision depends on specific associated tree canopy traits [25]. Beside the traits that enhance soil nutrient status, the importance of shade tree on cocoa production varies with the cropping season and precipitation pattern [26]. However, shade management is at the top of the list of practical farm challenges: the amount of shade is known to influence cocoa production [22], and it is difficult to estimate in CAFSs [27]. Thus, farmers' attitudes towards shade tree retention and management can be attributed to farm-specific challenges, the absence of a practical means of assessing the shade level, and distribution on farms. Hence, farmers could benefit from pragmatic guidance in deciding optimal shade levels for different tree density and diversity in CAFSs.

In this study, we evaluated the spatial configuration of cocoa trees across different plot rejuvenation phases and the contribution of associated shade trees to the CAFS rejuvenation pattern. We use the term 'plot' in reference to a sample area in CAFSs. We hypothesize that a clustering or randomness in horizontal structure of (young) cocoa trees is related to the density of associated trees and canopy gaps. Thus, temporal changes in spatial structure of these small cocoa trees may indirectly provide insights into trees' shade role attributed by farmers and how this is distributed at the farm scale. Thus, the following objectives were set: (1) assess variability in live woody biomass and tree abundance across an age gradient of traditional cocoa agroforests, (2) assess changes in the horizontal spatial structure of cocoa trees with plot age by comparing farms created from forests versus savannahs, (3) ascertain changes in farm rejuvenation across a temporal sequence of plot age, and (4) evaluate the spatial trade-off between farm rejuvenation with young cocoa trees and the density of associated non-cocoa trees. We envisage that this study will contribute to furthering our understanding of the dynamics in tree structure and management within CAFS and guide sustainable management strategies in cocoa landscapes.

\section{Materials and Methods}

\subsection{Study Site and Methods}

This study was conducted in the landscape of Bakoa $\left(40 \mathrm{~km}^{2}\right)$, which was found within the Bokito District ( $4^{\circ} 30^{\prime} \mathrm{N}$ and $11^{\circ} 10^{\prime} \mathrm{E}$; surface area of $7125 \mathrm{~km}^{2}$ ) of the Mbam and Inoubou Division in the Centre Region of Cameroon (Figure 1). Two main premises justify our choice of study: (1) situated in the forest-savannah transition zone [28], the landscape has a peculiar and fragile ecotone of vegetation which is sensitive to fluctuating weather patterns; (2) the peri-urban landscape, with a location of about $150 \mathrm{~km}$ from the country' $\mathrm{s}$ administrative capital (Yaoundé), features adapted and dynamic farming practises of both cash crop (mainly cocoa), and food for urban dwellers and market chains. The topography features a rolling terrain and the altitude ranges between 500 to $900 \mathrm{~m}$ a.s.1. The vegetation is a mosaic of bush-savannah, food crop fields, and agroforests. The latter, located mainly within or along patches of transition and gallery forests [29], features different shade-providing tree species associated with the cocoa crop: timber species such as Ceiba pentandra, Entandrophragma cylindricum, Pycnanthus angolensis, Milicia excelsa, Ficus spp., Albizia spp., etc.; fruit trees such as Elaeis guineensis, Citrus sinensis, Dacryodes edulis, Mangifera indica, Psidium guajava, etc.; trees providing NTFPs, such as Cola nitida, Garcinia kola, Ricinodendron heudelotii, Canarium schweinfurthii, etc.; and Musa spp. for food and temporary shade. The study area is situated in the humid forest bimodal agro-ecological zone, which is characterized by two dry and wet seasons. Observations by farmers indicate 
a growing variability in the onset and duration of the rains. The total annual rainfall ranges between 1300 and $1500 \mathrm{~mm}$, with a main rainy season from September to November; the short wet period is typically from April to June. The peak dry season lasts from December to March, while there is a short dry period from July to August. The mean annual temperature is $25^{\circ} \mathrm{C}$ [30].

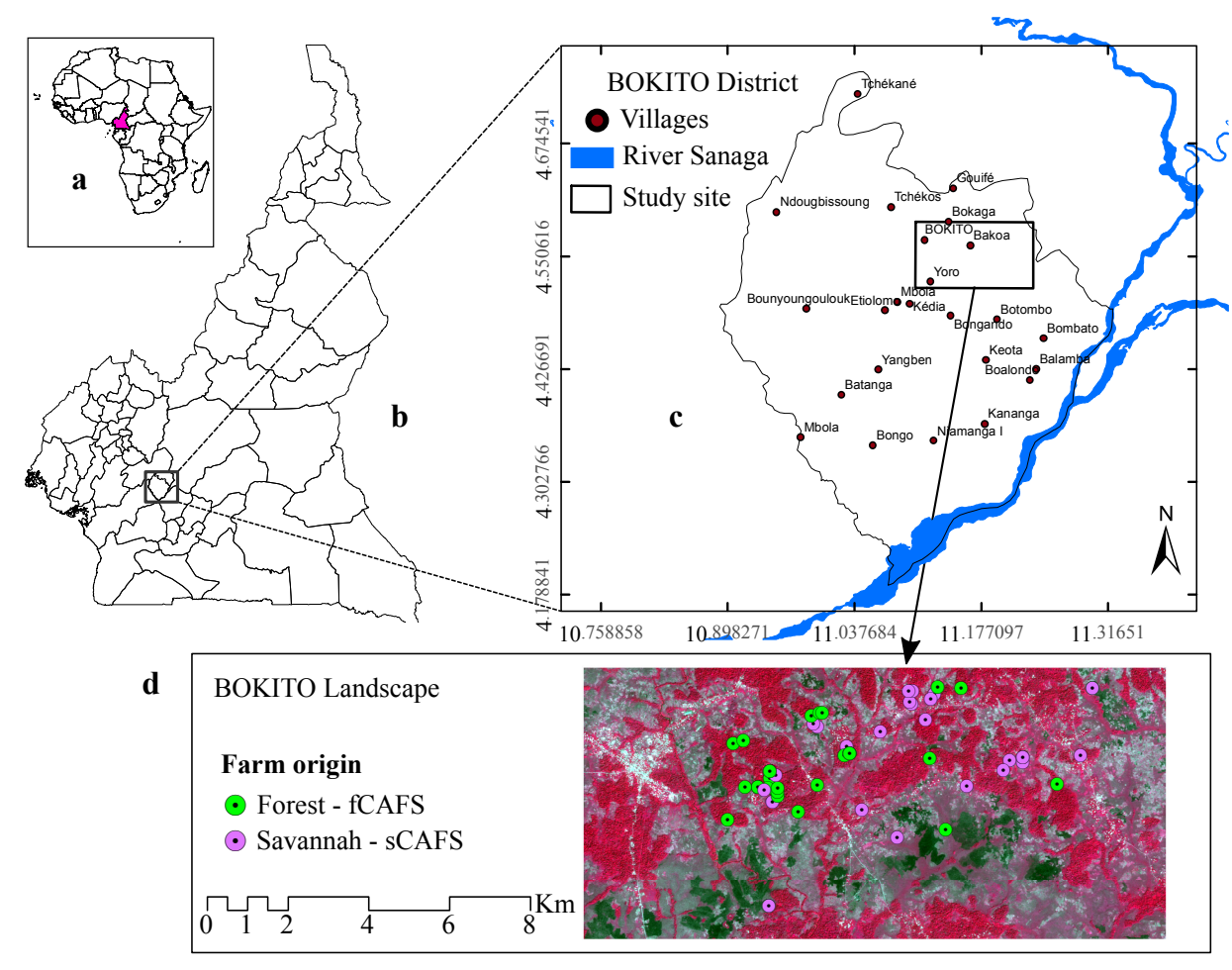

Figure 1. Location of the study site in the Bokito District Centre Cameroon. (a) Location of Cameroon in Africa. (b) Bokito District in the Mbam and Inoubou Division of the Centre Region of Cameroon. (c) Study area in the Bokito district. (d) Some cocoa agroforests in the study area, grouped by previous vegetation cover (farm origin), overlaid on a false color composite bands (RGB: Band5, Band3, and Band4) of RapidEye image (acquired on 9 January 2015) of the landscape (Source: a to c) WRI 2013 atlas of Cameroon, (d) author and FORSIT Laboratory).

\subsection{Field Sampling Scheme}

Small-scale cocoa producers, in 1-5 ha plantations, were consulted during reconnaissance field visits in 2016, and a list of cocoa producers was drawn based on local resource persons' knowledge. We used the framework in Figure 2 as a guideline in sampling cocoa agroforests, assessing temporal dynamics in ecosystem services and evaluating tree management and farm rejuvenation pattern in the study landscape. The farmer list, discussions with key informants, and the consideration that individuals often own two or more cocoa farms led to the following criteria in selecting sample farms:

1. Age of cocoa agroforestry farm-we selected at least one cocoa agroforestry parcel in each of the following age ranges [11]:
(a) $\leq 10$ years (immature plantation)
(b) 11-20 years (young plantation)
(c) 21-40 years (mature plantation)
(d) 41-60 years (old plantation), and
(e) >60 years (completely rejuvenated old plantation);

2. Farm management-only cocoa stands continuously managed as family farms, with the observed practice of agroforestry and tree diversification were included; and 
3. Farmer participation-sample farms were marked after consent from owner/managers, upon which access into the farm was granted.

Thirty-three CAFSs were selected during this study following discussions with local resource persons and farmers from a consulted list of farms involved in previous research projects. The number of sampled farms was not uniform across the age categories. The sample of immature and young cocoa farms was especially low because, in the region, the creation of new cocoa farms is rare. However, the presence of young cocoa trees in old and degraded plantations was obvious.

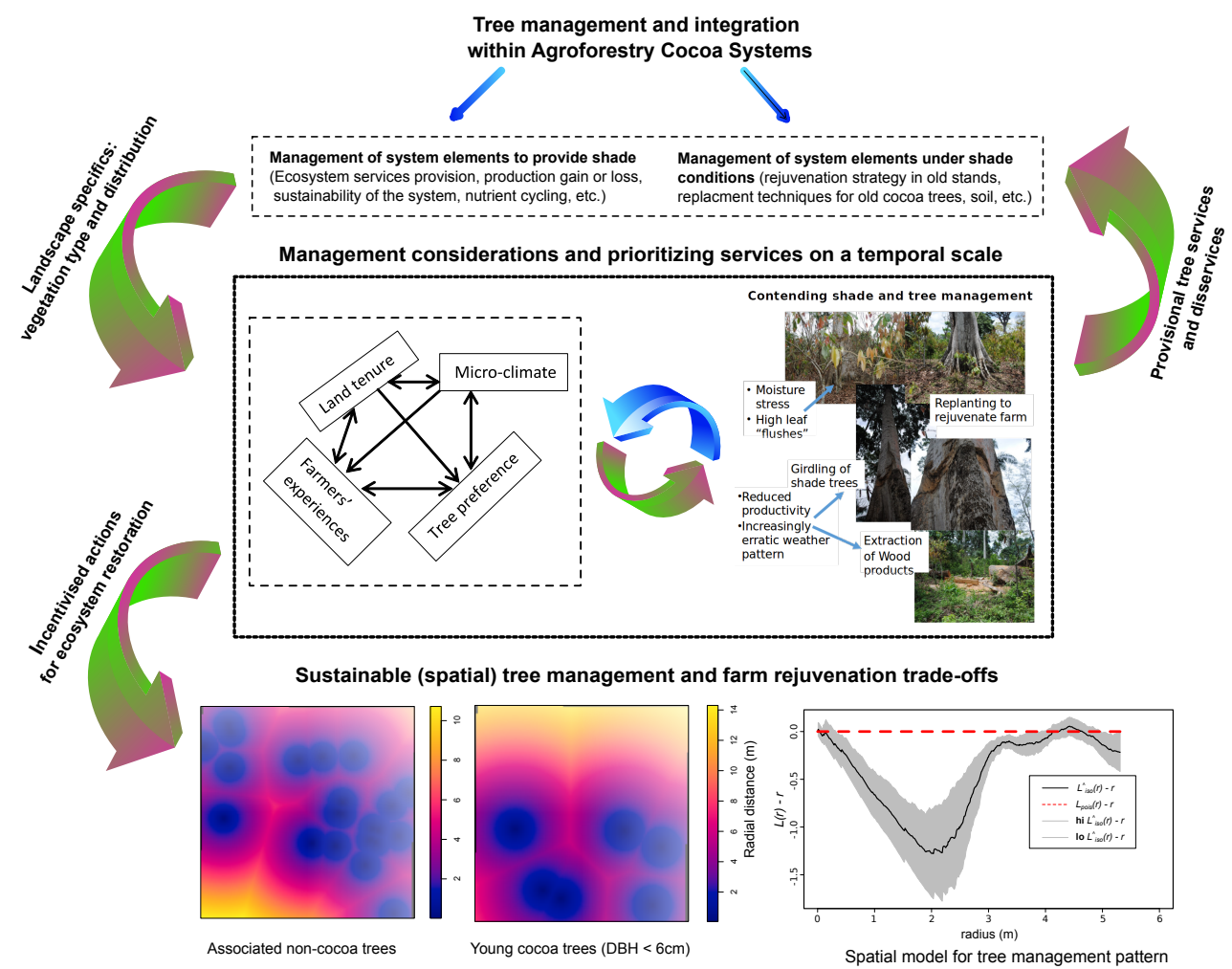

Figure 2. Framework for evaluating temporal farm rejuvenation pattern and modeling tree spatial configuration to inform about and incentivize sustainable tree management in CAFS and landscapes.

\subsection{Data Collection}

In 2016 and 2017, we sampled 61 plots of size $\approx 400 \mathrm{~m}^{2}(20 \mathrm{~m} \times 20 \mathrm{~m})$ in the 33 cocoa agroforestry (CAFS) family plantations spread across the study area. Cocoa plantations in the area are relatively small-scale (1-5 ha) (and often with irregular boundaries, as illustrated in Figure 3. Several different studies have used square plots of size $\approx 400 \mathrm{~m}^{2}$ to assess the structural attributes of forest stands such as tree density and basal area [31-35]. As suggested by Makeki et al. [35], small enough and simple to implement sampling plots are necessary to minimize measurement expenses, but importantly, they should be representative of the assessed stand. Moreover, circular or square plots may result in similar estimation accuracies depending on the measured stand structural parameter. Thus, a square plot of size $\approx 400 \mathrm{~m}^{2}$ was chosen as a trade-off between sample plot replication in each farm and the spatial variability in canopy structure. In both fCAFS and sCAFS, we set up sample plots in sections with observed variation in the canopy structure and the dominant type of shade trees (Figure 3). Cocoa agroforests often have a high variability in surface area and farm geometry [14,36]. The area and spatial extent of each CAFS were assessed on-site together with the farm managers and field resource persons. Then, a hand-held GPS was used to locate plot centres and to demarcate replicate sampling plots of approximately $20 \mathrm{~m} \times 20 \mathrm{~m}$ within the CAFS. The plots were oriented, whenever 
possible, in the north-south direction, and their locations were scaled to the shape and size of CAFS and chosen as far as possible from the farm boundaries. We sampled 33 and 28 plots, respectively, in fCAFS and sCAFS.

a
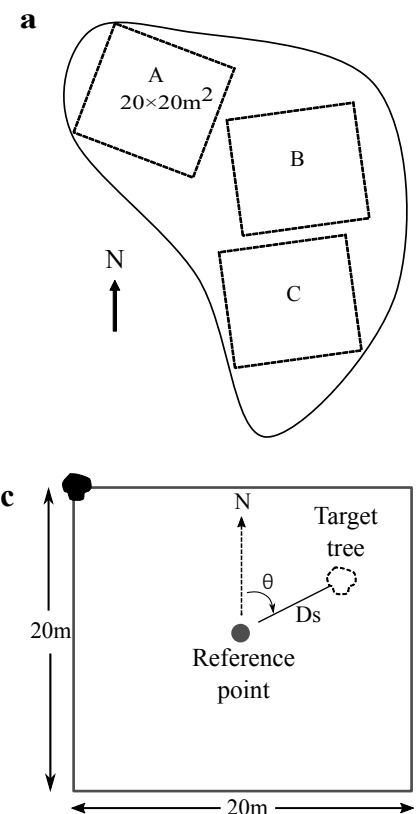

b

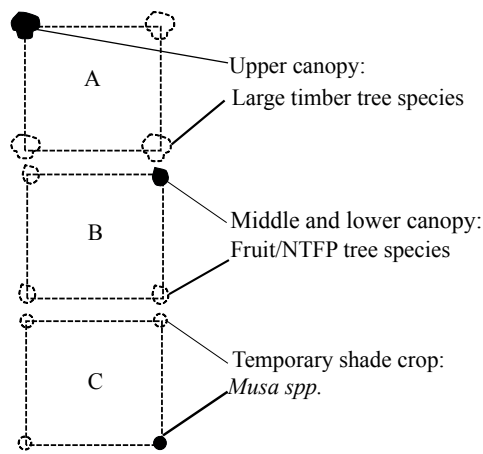

d

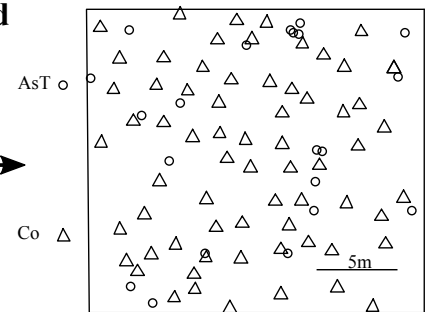

Figure 3. Sampling design used in the cocoa agroforests. (a) Sampling farm established based on variation in canopy structure and associated tree categories; (b) different associated tree species used as reference farm borders and in mapping; (c) illustration of tree mapping for a reference point in the centre of farm: the reference point alternated depending on the visual range to the target tree(s) $(\theta=$ bearing, in degrees, of target tree from magnetic north $(\mathrm{N})$ and Ds is distance from reference point); and (d) sample point pattern of the mapped trees in a farm. (source: author).

\subsubsection{Tree Mapping}

As tree diameter at breast height $(1.30 \mathrm{~m}), \mathrm{DBH}$, is linked with tree growth rate and age, it is easily recorded in the field. DBH for all cocoa trees and associated tree specimens was recorded using a diameter tape. Next to species name (or local name), we recorded their use(s). To map the tree location, we measured their bearing (in degrees) and distance (metres) from a reference point at either the centre point or one of the four edge points of each plot, which was previously identified with a Garmin 64 s GPS (Figure 3). The farm boundaries were also recorded with a GPS, while the position (bearing and distance) of cocoa and associated trees were recorded using a TruPulse 360R Laser rangefinder.

The larger cocoa trees represent the oldest specimen. They require less management attention and are often the least productive component on the farm. Thus, in order to assess the temporal pattern of farm rejuvenation by planting, we grouped cocoa trees into three diameter classes: (a) young cocoa trees ( $\mathrm{DBH}<6 \mathrm{~cm}$ ) - Coa1, (b) medium-sized cocoa trees (DBH 6-10 cm)-Coa2, and (c) large cocoa trees (DBH $>10 \mathrm{~cm})-$ Coa3.

The non-cocoa trees were also grouped into three categories based on their use: NTFP and Fruit trees (NtF), Timber trees (Tmb), and trees for temporary income, i.e., Musa spp. (Psud). Jagoret et al. [11] observed that the occurrence and pattern of associated trees varies with farm origin. The different associated trees (AsT) categories were analyzed further for temporal changes in their basal area share across farm age groups. We assume that such changes are an indicator of temporal shifts and dynamics in shade management. However, for basal area comparison between cocoa and other associated tree categories, we grouped all cocoa trees in each farm in one category (Co). For each plot, the total basal 
area $\left(\mathrm{m}^{2} \mathrm{ha}^{-1}\right)$ was calculated by summing the computed basal areas $(\mathrm{m})$ for all trees in which the stems were located within the plot.

\subsubsection{Above-Ground Live Woody Biomass (L-AGB)}

The inventory data included all standing and live woody and non-woody stems and twigs with DBH $>1 \mathrm{~cm}$ in the sampled plots. From the diameter measurements, we estimated the above-ground biomass (AGB) of living trees using a nondestructive method and using the allometric equation of the BIOMASS package in R software [37]. This is illustrated by Equation (1). Since estimates of tree height are, in general, difficult under conditions of multi-strata and overlapping canopies, the equation fits a tree heightdiameter allometry to retrieve height values and compounds metrics of WD and $\mathrm{E}$ to estimate above-ground biomass [38]. We retrieved the wood density from the Global Wood Density Database [39] and the environmental variables according to Chave et al. [38]. For unidentified trees species or those without a reference for wood density, we used a global average of $0.615 \mathrm{~g} \mathrm{~cm}^{3}$, as in [40]. In the AGB estimation, we excluded Musa spp., non-woody tree such as oil palm and coconuts trees, and dead trees. Thus, the estimated biomass was the live wood AGB (lwAGB).

$$
A G B=\exp \left(-2.024-0.896 \times E+0.9220 \times \ln (W D)+2.795 \times \ln (D)-0.0461 \times\left[\ln (D)^{2}\right]\right)
$$

where $\mathrm{DBH}(D)$, wood density $(W D)$, and environmental or climatic parameter $(E)$.

The environmental parameter, $E$, was estimated using Equation (2). It is a bio-climatic stress variable, which is a linear function of three climatic indices: temperature seasonality (TS), precipitation seasonality (PS), and climatic water deficit (drought intensity) (CWD). The parameter was developed based on a pan-tropical database, and biomass models based on the $E$ are applicable in tree-dominated vegetation types across tropical regions [38].

$$
E=(0.178 \times T S-0.938 \times C W D-6.61 \times P S) \times 10^{-3}
$$

\subsection{Data Analysis}

\subsubsection{Analysis of Farm Structural Dynamics}

Exploratory data analysis to identify the characteristic differences in farm management across the sampled CAFS was conducted at two levels: first, tree structural composition in sample plots, based on estimates of tree density and above-ground biomass of the different tree categories. We removed plots for which one or more of the measured or estimated tree density and biomass variables exceeded three standard deviations from the mean-as outliers. We used seven variables for tree density per hectare: density of the four, previously classified cocoa tree categories; density of non-cocoa trees (Ast); total tree density in each plot; and total basal area $\left(\mathrm{m}^{2} \mathrm{~h}^{-1}\right)$. Then, we used four variables related to plot biomass: cocoa trees (Co.AGB), timber trees (Tmb.AGB), fruit and NTFP trees (NtF.AGB), and all trees $(w A G B)$. We used the nonparametric multi-dimensional scaling (NMDS) descriptive statistics of the Vegan library in $R$ to assess structural dynamics with plot age and origin. All of the measured variables did not respect the assumption for a parametric correlation test based on the Shapiro-Wilk test of normality (at $p<0.05$ ) (Table S1 in Supplementary Material). Thus, we tested for significant correlations between the variables using a bootstrap Spearman correlation test with 1000 replications. Second, we used a nonparametric Wilcoxon test and the Bonferroni adjustment for multiple comparisons p-value to test significant differences in the mean values between the plot age groups, separately for fCAFS and SCAFS.

\subsubsection{Horizontal Spatial Pattern of Trees within CAFS}

Cocoa agroforests have similar management regimes of weeding and sanitary spraying across regions [30], and the structure generally comprised two to three canopy storeys across production landscapes [14]. Thus, focusing on the horizontal structure in individual 
CAFS may help improve the analysis of the spatial pattern trees and temporal changes in cocoa agroforests.

The spatial point pattern analysis has been used in the field of forestry and ecology to assess and model spatial structure trees and ecological phenomena of interest [41-43]. The application of such analysis in agroforestry to assess configurations between associated trees and cocoa trees focused only on young cocoa plantations [44]. However, this approach requires a minimum of 10 spatial points, which is constraining for typical cocoa agroforests - with a low density of associated trees.

In this study, we mapped trees (as spatial point patterns) and assessed their spatial dependence through mixed effect models [45], an approach that is not constrained by a threshold density of trees. All of the mapped locations of cocoa and associated trees in a sample plot were converted to a representative spatial point pattern of trees within the plot. Spatial point pattern analysis has been used in various ecological investigations including agroforestry [44] using the Ripley $K_{(r)}$ function [46]. Then, the univariate $L_{(r)}$ function for all the cocoa trees within each sampled plot was computed, and an isotropic plot edge effect correction was considered [46]. The details about these functions and how they were applied are provided in the Supplementary Materials.

\subsubsection{Temporal Dynamics in CAFS Rejuvenation}

We fitted a mixed poisson model to the point patterns of young cocoa trees (DBH $<6 \mathrm{~cm}$ ) using the multi-point process module (mppm) in spatstat package [45] to ascertain differences in young cocoa tree density between plot age groups and the variability among plots within each group (details in the online Supplementary Material). The assumptions for the poission model were tested based on homogeneity in the distributed point pattern. Since the distribution of both the associated and young cocoa tree were not homogeneous in each plot, we applied the inhomogeneous K-function to estimate their spatial patterns. We used the distance to associated trees (dAsT) as spatial covariates to assess their contribution to the spatial location of young cocoa trees. We assumed a random intercept and slope for plot age group (i.e., spatial covariates were assumed to have random slopes across plot age). To assess the temporal changes and spatial variability in plot rejuvenation in relation to the density of AsT, we predicted the density of the young cocoa trees for increasing the distance from AsT. We validated the models by examining the distribution of the raw residuals for the plot age groups. Furthermore, the influence of the spatial covariate was tested using the Kolmogorov-Smirnov test of goodness of fit for the inhomogeneous Poisson model, the spatial cumulative distribution function (CDF) test [45].

\section{Results}

\subsection{Dynamics of Tree Structure at the Farm Scale}

Tables 1 and 2 offer a comparison of the tree structure, relative abundance (basal area), and biomass between the age groups of plots in the fCAFS and sCAFS categories. For both farm categories, the density of cocoa trees generally decreased with plot age. The highest cocoa density was on immature fCAFS (1114 trees ha $\left.{ }^{-1}, n=5\right)$ and young sCAFS plots $\left(1544\right.$ trees ha $\left.{ }^{-1}, n=5\right)$. The density of young cocoa trees $(\mathrm{DBH}<6 \mathrm{~cm})$ was generally high in young plots of sCFAS (782 trees ha ${ }^{-1}, n=3$ ). This represented about $61 \%$ of cocoa trees on SCFAS at this age and was not significantly higher than that on rejuvenated old plots (range of 217-243 trees ha ${ }^{-1}$ ) (Table 2). Conversely, for fCAFS, the mature plots had the highest density of young cocoa (415 trees ha ${ }^{-1}, n=8$ ), which accounted for about $40 \%$ of the cocoa trees. The density of associated shade trees did not vary significantly between plots age groups, but it was generally high in mature cocoa plots. When the sampled plots were analyzed for farm origin, the average density of non-cocoa companion trees (AsT) was, as expected, higher in fCAFS (345 trees ha $\left.{ }^{-1}, n=8\right)$ compared to sCAFS (204 trees $\left.\mathrm{ha}^{-1}, n=4\right)$. The lowest density of associated trees varied from 146 trees ha $^{-1}(n=5)$ in old sCAFS plots (41-60 years) to 184 trees ha $^{-1}(n=9)$ in young plots of fCAFS. 
Table 1. Summary of the tree structure, tree abundance, and ecosystem service in plots of fCAFS, estimated, respectively, by tree density (trees ha $\left.{ }^{-1}\right)$, basal area $\left(\mathrm{m}^{2} \mathrm{ha}^{-1}\right)$, and live wood AGB $\left(\mathrm{Mg} \mathrm{C} \mathrm{ha}^{-1}\right)$. The reported statistics are means with standard deviation, $\mathrm{SD}$, in parentheses.

\begin{tabular}{|c|c|c|c|c|c|}
\hline & \multicolumn{5}{|c|}{ Plot Age Group } \\
\hline & $\leq 10$ years & $11-20$ & $21-40$ years & $41-60$ years & $>60$ years \\
\hline \multicolumn{6}{|l|}{ Tree density } \\
\hline AsT.ha & $251.4(21.5)$ & $184.2(84.9)$ & $345.8(329.6)$ & $209.5(129.5)$ & $253.3(127.9)$ \\
\hline Coa1.ha & $275(247.1)$ & 276.7 (116.9) & 415.8 (202.9) & $329.8(240.0)$ & $217.3(144.1)$ \\
\hline Coa2.ha & $752.4(116.4)$ & 694.7 (247.5) & 450.1 (191.2) & $435.4(147.5)$ & $397.0(189.2)$ \\
\hline Coa3.ha & $92.3(41.3)$ & $141.8(68.9)$ & $153.1(166.2)$ & $278.8(59.5)$ & $222.3(86.5)$ \\
\hline Coa4.ha & $1114.7(120.8)$ & $1109.3(263.1)$ & $1040.2(229.1)$ & $1039.8(335.7)$ & 836.7 (303.8) \\
\hline Trees.ha & $1366.0(114.4)$ & $1293.5(324.3)$ & $1386.0(363.8)$ & $1249.4(356.4)$ & $1090.0(253.8)$ \\
\hline Tree BA.ha & $24.1(20.3)$ & $33.4(27.3)$ & $57.3(51.1)$ & $182.0(252.9)$ & $41.1(42.3)$ \\
\hline \multicolumn{6}{|c|}{ Live wood biomass (L-AGB) } \\
\hline Co.AGB & $19.0(4.5)$ & $18.9(6.6)$ & 16. $(7.6)$ & $22.4(4.6)$ & $21.5(7.6)$ \\
\hline NtF.AGB & $34.9(31.5)$ & $81.3(148.1)$ & $24.9(25.0)$ & $53.9(57.5)$ & $77.2(50.5)$ \\
\hline Tmb.AGB & 86.4 (138.2) & $171.8(204.1)$ & $442.9(574.0)$ & $2138.1(3198.0)$ & $137.8(212.6)$ \\
\hline wAGB & 141.9 (147.5) & $272.1(256.6)$ & $483.9(563.1)$ & 2214.6 (3159.3) & $236.6(224.6)$ \\
\hline
\end{tabular}

Coa1.ha $=$ Density $\left(\right.$ trees $\left.\mathrm{ha}^{-1}\right)$ of young cocoa trees $(\mathrm{DBH}<6 \mathrm{~cm})$, Coa2.ha $=$ Density of medium-sized cocoa trees $(\mathrm{DBH} 6-10 \mathrm{~cm})$, Coa3.ha $=$ Density of large cocoa trees $(\mathrm{DBH}>10 \mathrm{~cm})$, Coa4.ha $=$ Density of cocoa trees, Trees.ha $=$ Total density of all trees, Tree BA.ha $=$ Basal Area of all trees, Co.AGB = Above-ground biomass of cocoa trees, NtF.AGB = AGB of fruit and NTFP trees, Tmb.AGB = AGB of timber tree species, and wAGB.ha $=$ AGB of all wood trees.

Table 2. Summary of tree density (trees ha $\left.{ }^{-1}\right)$, basal area $\left(\mathrm{m}^{2} \mathrm{ha}^{-1}\right)$ and live wood AGB $\left(\mathrm{Mg} \mathrm{C} \mathrm{ha}^{-1}\right)$ in plots of sCAFS. The reported statistics are same as on Table 1. and where noted, the different superscript letters on the SD denote significant difference (Wilcoxon test at $p<0.05$ with Bonferroni corrected alpha level) between the plot age groups.

\begin{tabular}{|c|c|c|c|c|c|}
\hline & \multicolumn{5}{|c|}{ Plot age group } \\
\hline & $\leq 10$ years & $11-20$ years & $21-40$ years & 41-60 years & $>60$ years \\
\hline \multicolumn{6}{|l|}{ Tree density } \\
\hline AsT.ha & $152.5(37.9)$ & $178.8(92.9)$ & $204.3(67.9)$ & $146.1(45.5)$ & $162.1(67.8)$ \\
\hline Coa1.ha & $152.5(37.9)$ & $178.8(92.9)$ & $204.3(67.9)$ & $146.1(45.5)$ & $162.1(67.8)$ \\
\hline Coa2.ha & 464.3 (181.3) & $654.8(191.5)$ & $433.8(269.4)$ & $565.5(204.3)$ & 410.7 (141.7) \\
\hline Coa3.ha & $31.4(18.9)$ & $157.6(104.0)$ & $239.8(138.7)$ & $157.3(122.8)$ & $324.3(94.2)$ \\
\hline Coa4.ha & $1278.2(157.1)$ & $1544.5(588.2)$ & $995.4(345.60)$ & $978.4(230.6)$ & 970.3 (218.5) \\
\hline Trees.ha & 1430.7 (195.0) & $1723.3(551.3)$ & 1199.7 (307.2) & $1124.5(264.1)$ & $1132.4(39.9)$ \\
\hline Tree BA.ha & $11.9(2.1)$ & $17.2(10.2)$ & $64.9(85.1)$ & $27.5(32.9)$ & $112.9(186.5)$ \\
\hline \multicolumn{6}{|c|}{ Live wood biomass (L-AGB) } \\
\hline Co.AGB & $10.2(2.3)$ & $23.2(11.2)$ & $24.9(5.3)$ & $19.8(7.1)$ & $28.4(6.3)$ \\
\hline NtF.AGB & $46.9\left(40.1^{a b}\right)$ & $33.9\left(43.3^{a b}\right)$ & $140.9\left(83.5^{a}\right)$ & $59.7\left(30.8^{a b}\right)$ & $16.6\left(14.4^{b}\right)$ \\
\hline Tmb.AGB & - & $55.5(51.1)$ & $390.6(763.1)$ & $65.8(138.4)$ & $1044.9(2097.7)$ \\
\hline wAGB & $57.1(42.4)$ & $112.9(70.5)$ & $556.5(843.7)$ & $145.3(131.7)$ & $1089.9(2096.2)$ \\
\hline
\end{tabular}

The abbreviations are the same as on Table 1.

\subsubsection{Temporal Variability in Tree Abundance and Live Biomass}

The tree basal area on both fCAFS and sCAFS plots was not significantly different between plot age groups (Tables 1 and 2). The basal area share of trees types differed with the age of plots, with different trends for fCAFS and sCAFS (Figure 4). In fCAFS, the basal area proportion of the timber trees was dominant across the plot age groups. However, their mean basal area was inconsistent across plot age groups: $11.07 \mathrm{~m}^{2} \mathrm{ha}^{-1}$ in young plots ( $\leq 10$ years) and $44.44 \mathrm{~m}^{2} \mathrm{ha}^{-1}$ in the oldest ones ( $>60$ years) (Figure $4 \mathrm{a}$ ). 
For the sCAFS farm category, $\mathrm{NtF}$ and cocoa trees on plots aged below 20 years and timber trees on plots above 40 years (Figure $4 \mathrm{~b}$ ) contributed the highest proportion of basal area. On fCAFS-derived plots, the live biomass of cocoa trees was not significantly different between the plot age groups.
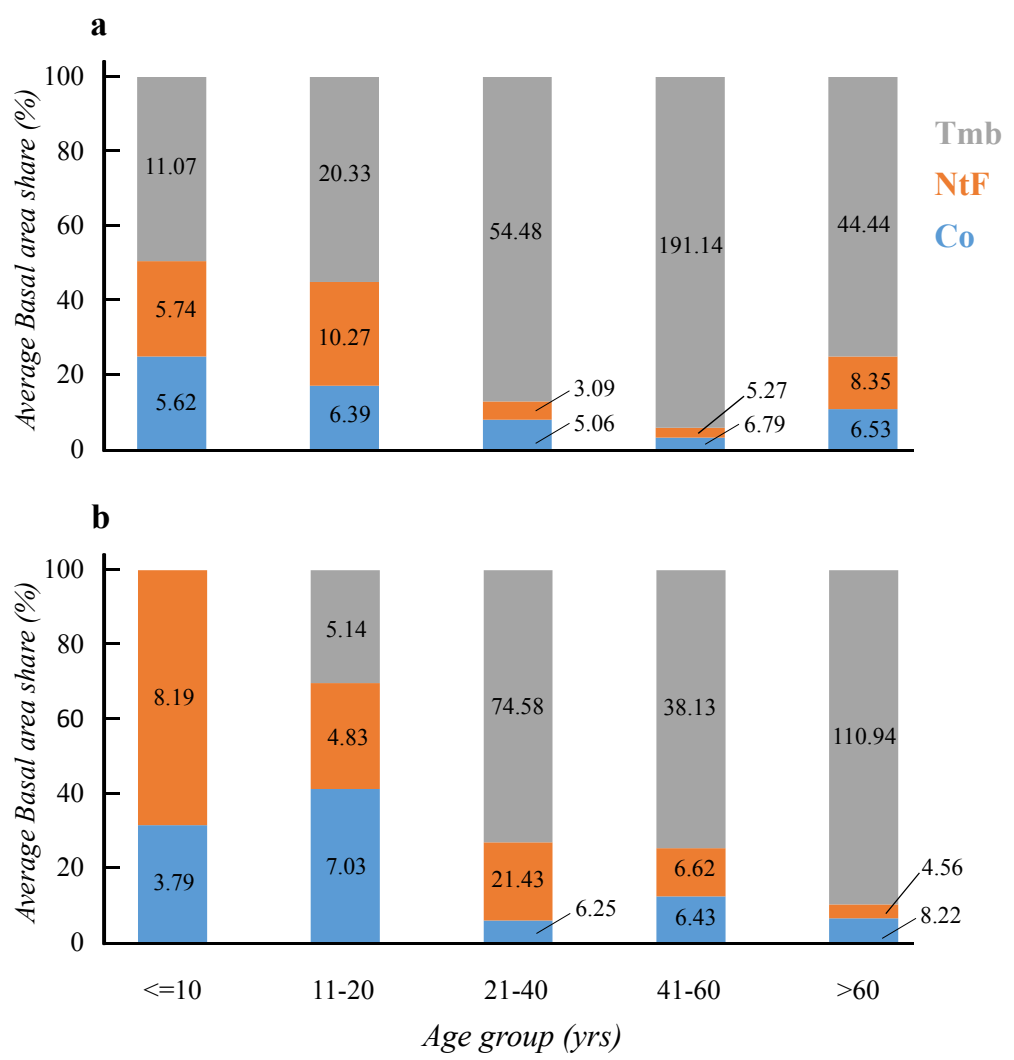

Figure 4. Relative abundance (basal area proportion) of woody trees categories across a gradient of plot age. (a) fCAFS. (b) sCAFS. The shaded portions of each bar represent the average basal area share $(\%)$ of the different tree categories: Cocoa trees-Co, Fruit and NTFP trees-NtF, and Timber trees-Tmb.

\subsubsection{Synergy between Live Woody Biomass and Cocoa Tree Density}

There was no discernible correlation between the AGB and density of cocoa trees (Figure 5a). The AGB of cocoa trees correlated negatively with density of associated trees. However, this link was insignificant $(p=0.214)$, with varying trend for different plot ages (Figure $5 b$ ). These observations are confirmed by the $95 \%$ CI of the bootstrap Spearman correlation coefficients, which cross zero (Figure $5 c$,d). In general, the live woody biomass did not correlate with the density of trees (Figure 6a) as, again, confirmed by the $95 \% \mathrm{CI}$ of the correlation coefficient in Figure 6b. 

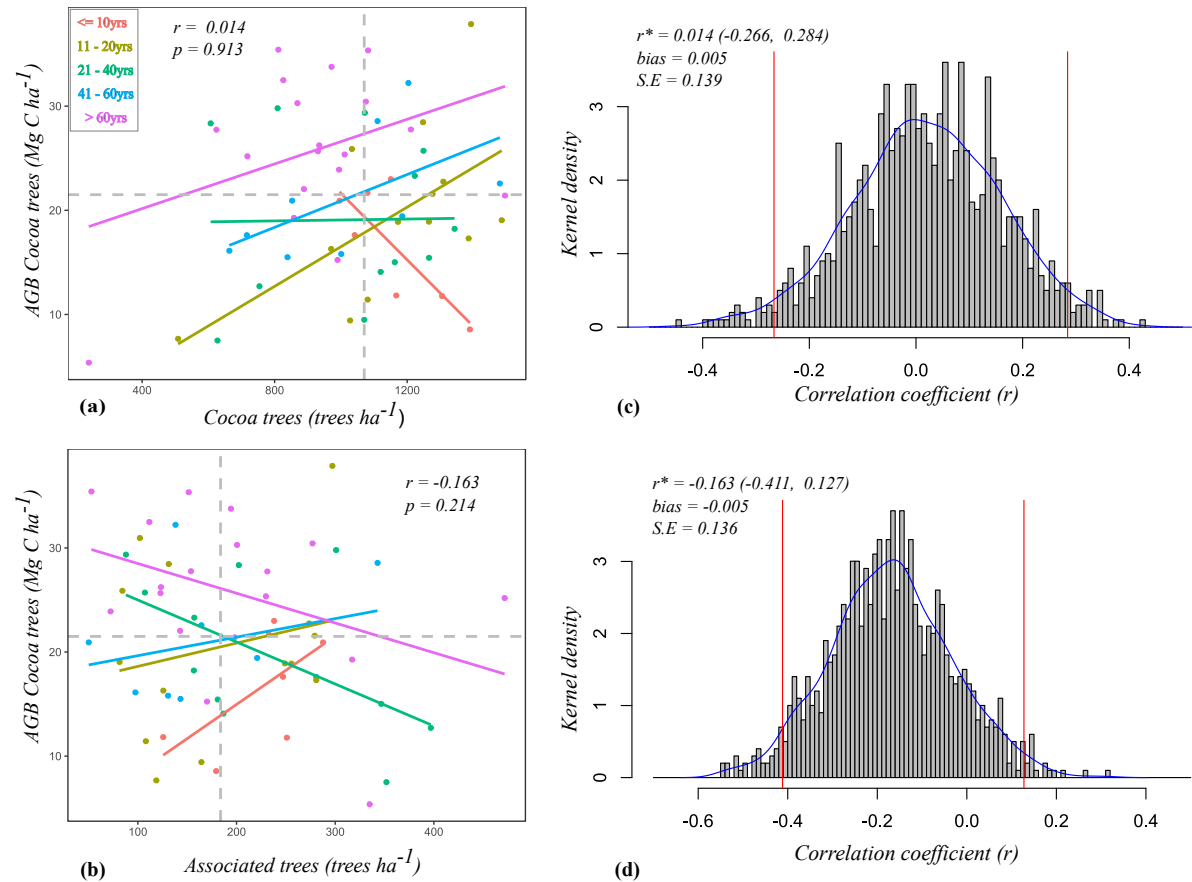

Figure 5. Relationship between live AGB of cocoa tree and density of non-cocoa trees in 59 CAFS plots of different age groups following a Spearman correlation test. (a) No significant relationship was found with between AGB and density of cocoa trees. (b) No significant correlation with the density of associated trees, and there are contrasting gradients between plots age groups. (c,d) Histograms of bootstrap Spearman correlation tests for, respectively, (a,b) based 1000 bootstrap samples. The density plot by Gaussian kernel smoothing is shown by the blue lines, and the red lines indicate the 95\% confidence interval (CI) of the bootstrap correlation coefficient with a mean value of $\mathrm{r}^{*}(95 \% \mathrm{CI})$. The dash grey lines are the overall medians, and the different colours represent the plot age groups.

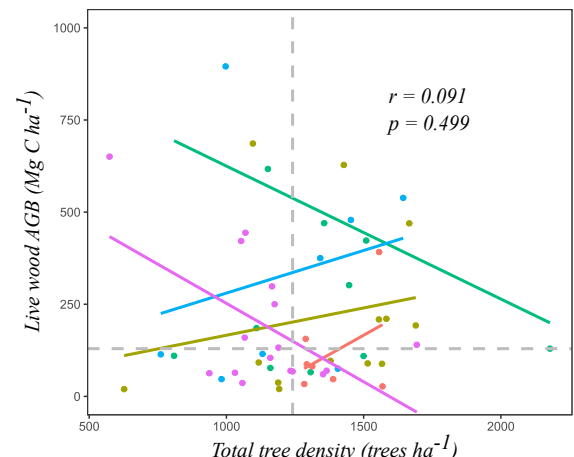

(a)

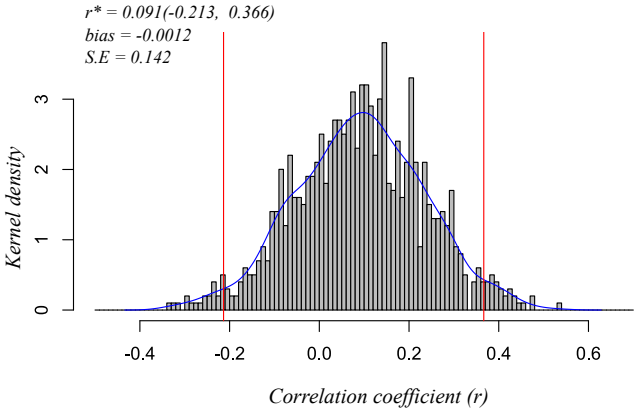

(b)

Figure 6. The relationship between live wood biomass and tree density. (a) Scatter plot and Spearman correlation between live biomass and tree density in the sampled plots highlight opposite gradients in young versus old plots. The grey dashed lines are the overall medians for the variable in each axis, and the different colours represent the plot age groups. (b) Histogram of the bootstrap Spearman correlation test with 1000 replications. The blue lines are the density plot by Gaussian kernel smoothing, and the red lines indicate the $95 \% \mathrm{CI}$ of the bootstrap correlation coefficient with a mean value of $\mathrm{r}^{*}(95 \% \mathrm{CI})$. 


\subsection{Temporal Dynamics of Farm Structure}

From NMDS ordinations of tree structural composition and wood biomass in the 59 sampled plots, there was no clear clustering (high overlap of the confidence interval (CI) ellipses) both in relation to plot origin and age gradient (Figures 7 and 8 ). The tree basal area was not associated with plot age and origin (Figure 7). The density of associated trees was similar on fCAFS plots in age range 20-40 years (Figure 7a). The non-cocoa companion trees were abundant on fCAFS plots in the age range of $11-40$ years, and the large cocoa trees were prominent on old plots of sCAFS. The farm structure and tree abundance was similar on both farm types, but high variations were observed on plots below 11 years and between 40-60 years. The wide range of the NMDS ordination space, as apparent from the volume of the ellipses, indicates a generally high variation in farm structure and biomass both within plot age groups and among farm types (Figures 7c,d and $8 \mathrm{c}, \mathrm{d}$ ). However, considering the volume of the NMDS CI ellipses (Figure 7d), the farm structure was less variable on fCAFS than on sCAFS plotss, and the same is visible on young plots (11-20 years) (Figure 7c). The relative tree abundance and biomass was stable in the rejuvenated old plots ( $>60$ years). The large overlap of the CI ellipses (Figures $7 \mathrm{~d}$ and $8 \mathrm{~d}$ ) is indicative of the structural similarity between fCAFS and sCFAS on a temporal scale.
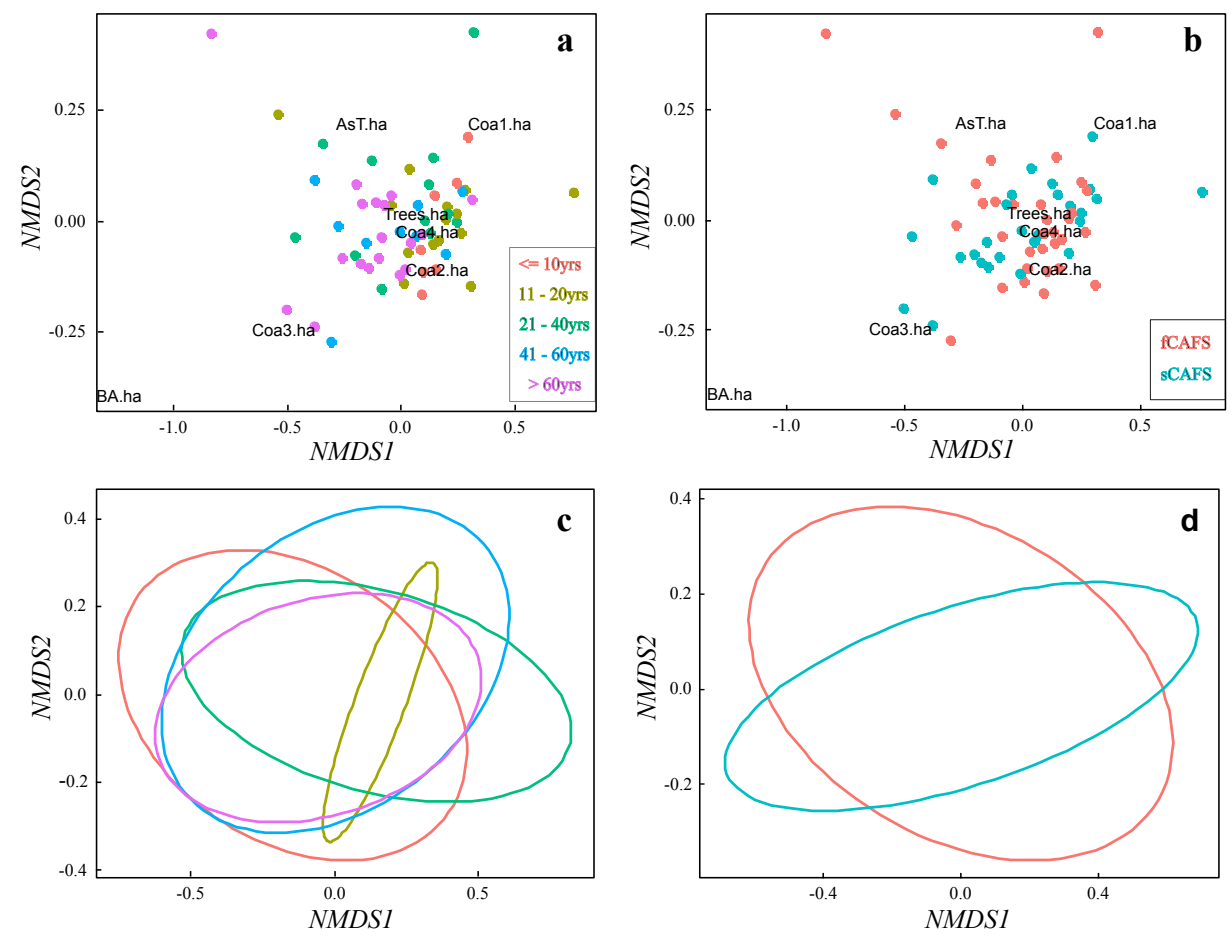

Figure 7. Two-dimensional (2-D) non-metric multidimensional scaling (NMDS) chart for the structural composition of trees in 59 plots of size $20 \mathrm{~m} \times 20 \mathrm{~m}$ organized into seven tree categories, estimated per hectare. (a) Composition of plots by age groups. (b) Composition of plots by categories. The variability in tree structure for each plot age group is shown by the $95 \%$ CI ellipses around mean NMDS1 and NMDS2: (c) within plot age group; (d) within farm category. The NMDS Ordination stress $=0.091$ and $k=2$. Colours in $(\mathbf{a}, \mathbf{c})$ indicate plot age group, and those in $(\mathbf{b}, \mathbf{d})$ are farm category. The tree categories, superimposed in $(\mathbf{a}, \mathbf{b})$, are described in Table 1. 

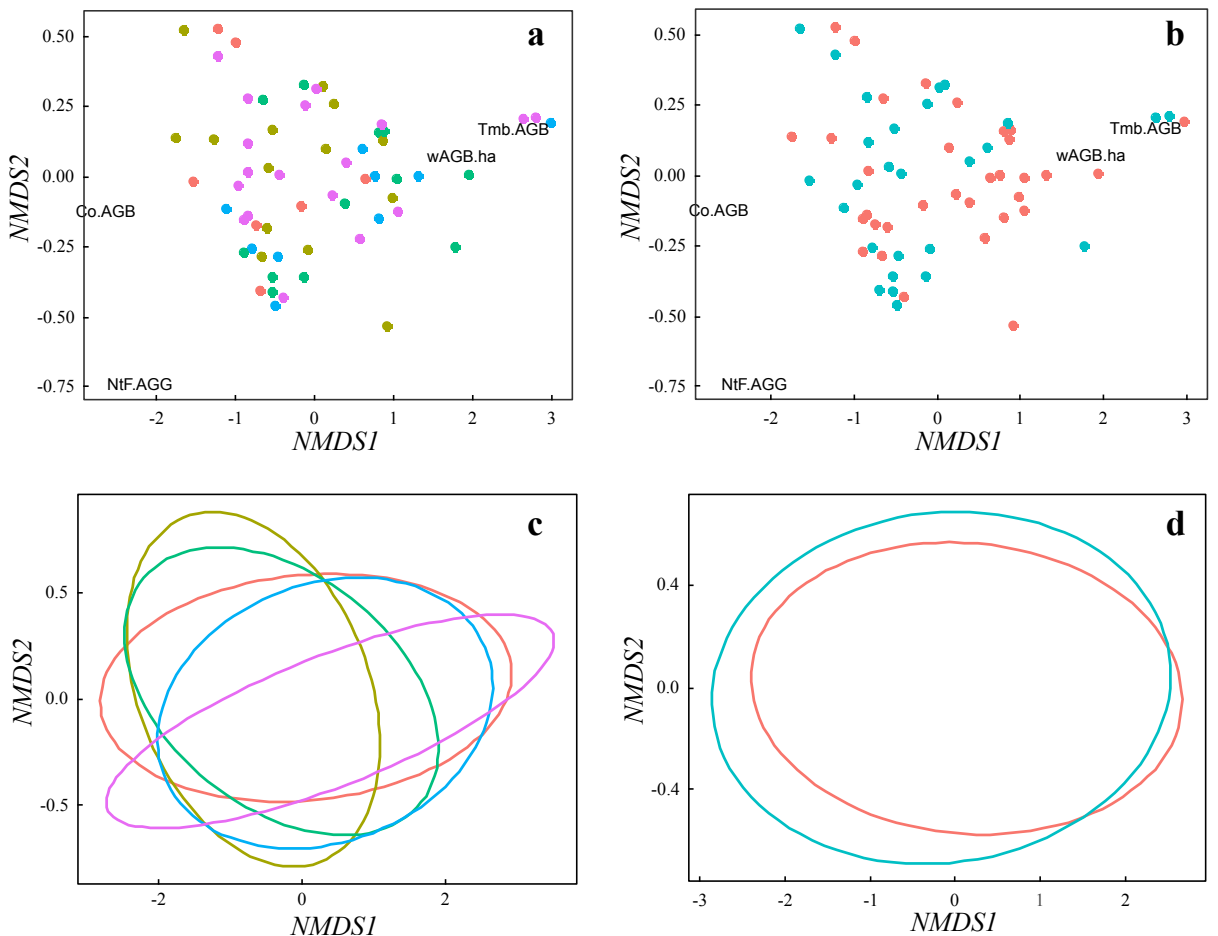

Figure 8. Two-dimensional NMDS results for above-ground live woody biomass (lwAGB) aggregated into four tree categories, for the 59 plots of size $20 \mathrm{~m} \times 20 \mathrm{~m}$. (a) Biomass composition by farm age-groups. (b) Biomass composition by farm categories. The tree categories, estimated per hectare, are superimposed in black text. The NMDS1 versus NMDS2 variation in farm structure is shown by the 95\% CI ellipses: (c) variation within farm age-group; (d) variation within farm category. The NMDS Ordination stress $=0.029, \mathrm{k}=2$. The colour legend is the same as in Figure 7 .

\subsection{Horizontal Structure of Cocoa Tree Management}

The minimum spacing between cocoa trees decreased with the age of fCAFS plots. Conversely, this spacing increased with the age of the plot in sCAFS (Figure 9a). Remarkably, a plot with reduced spacing between cocoa trees had a random configuration of cocoa trees at a cummulative distance of $3 \mathrm{~m}$ : fCAFS plots in the age range 21-60 years and sCAFS plots below 21 years. Thus, cocoa production in association with other tree species may eventually require random configuration of cocoa trees; cocoa agroforestry models on tree configuration may be developed in this light. The maximum distance between cocoa and associated trees was stable in both fCAFS and sCAFS plots of different ages (Figure 9b,d). The minimum spacing between AsT varied across age for both the fCAFS and sCAFS plots (Figure 9c). Thus, variations in the configuration of trees in the sampled plot was influenced by differences in the minimum spacing between trees. This is indicative of intensive management practices such as varying the density of either cocoa or associated trees.

The linearized L-function $\left(L i_{(r)}-r\right)$ reveals that, in immature and young cocoa plots of fCAFS, cocoa trees are planted or managed in regular spacing at much smaller spatial and the cumulative effect was still evident at a radial distance of $3 \mathrm{~m}$. The spatial spatial configuration of cocoa trees was consistent with a regular distribution up to a distance of $4 \mathrm{~m}$ (Figure 10a,b). Thus, we suggest that, in the young fCAFS plots, cocoa trees are managed at regular planting spacing irrespective of other associated trees. In the mature and older fCAFS plots, a random distribution of cocoa trees was evident from a cumulative distance of $3 \mathrm{~m}$ and beyond. For sCAFS, the spatial pattern of cocoa trees correlated with a random distribution at distance of $3 \mathrm{~m}$ or more in plots below 40 years (Figure 10f-h). The configuration was, however, different for mature sCFAS plots; a spatial pattern that correlates with random distribution was evident from a distance $2.5 \mathrm{~m}$ onwards. These 
observations indicate a high variability in the spatial configuration of cocoa trees in CAFS. Based on the tree density, the estimated average spacing between cocoa trees was uniform across plot age (Table 3). The average spacing between non-cocoa companion trees varied with farm age and was generally high on sCAFS-derived plots.

Table 3. Estimates of average spacing $(\mathrm{m})$ between different tree categories on plots (in fCAFS versus sCAFS) of different age groups based on observed tree density and a scenario of planted cocoa trees in a regular square configuration.

\begin{tabular}{lccccc}
\hline & \multicolumn{5}{c}{ Plot Age Group } \\
\cline { 2 - 6 } & $\leq \mathbf{1 0}$ years & $\mathbf{1 1 - 2 0}$ years & $\mathbf{2 1 - 4 0}$ years & $\mathbf{4 1 - 6 0}$ years & >60 years \\
\hline fCAFS & & & & & \\
Cocoa trees & 3.0 & 3.0 & 3.1 & 3.1 & 3.5 \\
Non-cocoa trees & 6.3 & 7.4 & 5.4 & 6.9 & 6.3 \\
All trees & 2.7 & 2.8 & 2.7 & 2.8 & 3.0 \\
sCAFS & & & & & \\
Cocoa trees & 2.8 & 2.5 & 3.2 & 3.2 & 3.2 \\
Non-cocoa trees & 8.1 & 7.5 & 7.0 & 8.3 & 7.9 \\
All trees & 2.6 & 2.4 & 2.9 & 3.0 & 3.0 \\
\hline
\end{tabular}
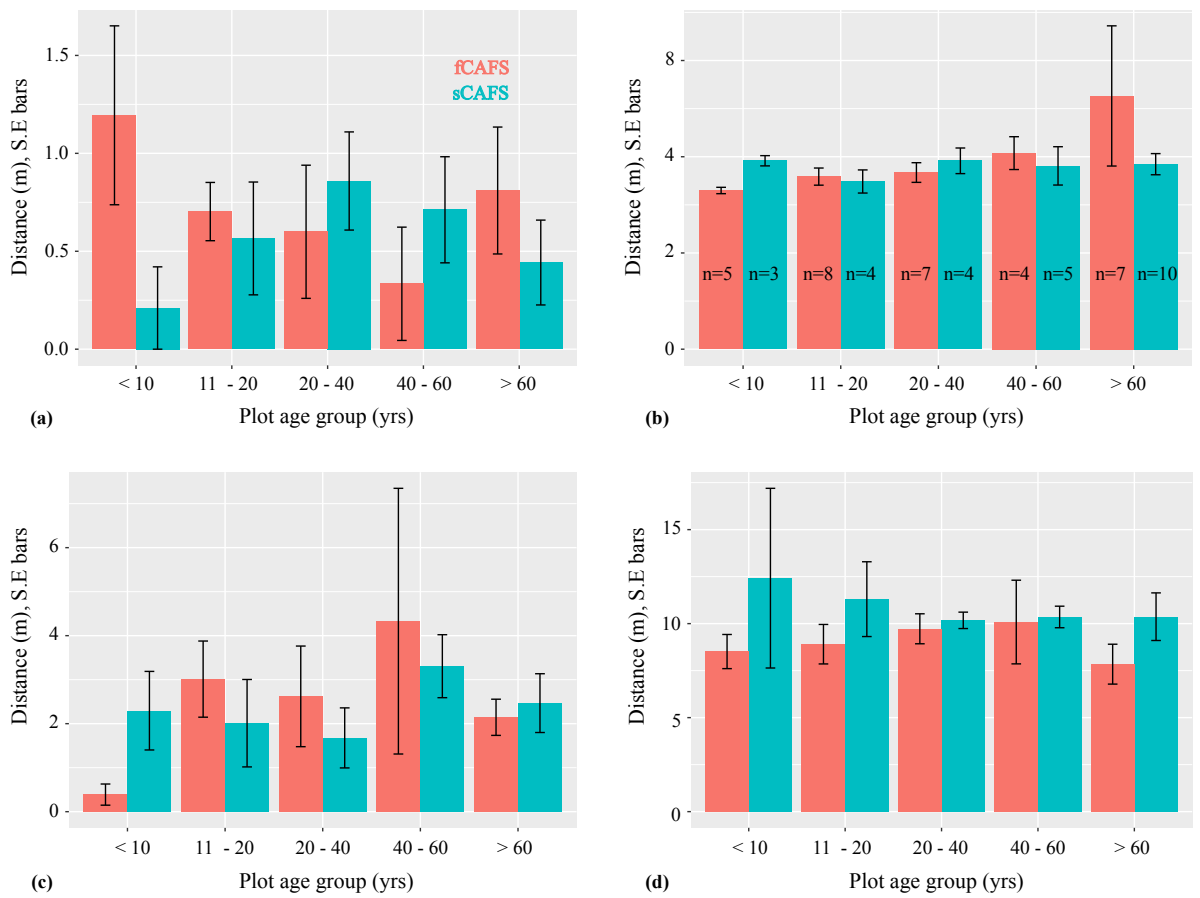

Figure 9. Bar plots of the average spacing between young cocoa tree and associated trees in the sample plots. (a) Minimum distance between cocoa trees. (b) Maximum distance between cocoa trees. (c) Minimum distance between associated trees. (d) Maximum distance between associated trees. (The error bars represent the S.E of the mean). 
Farms from Forest - fCAFS
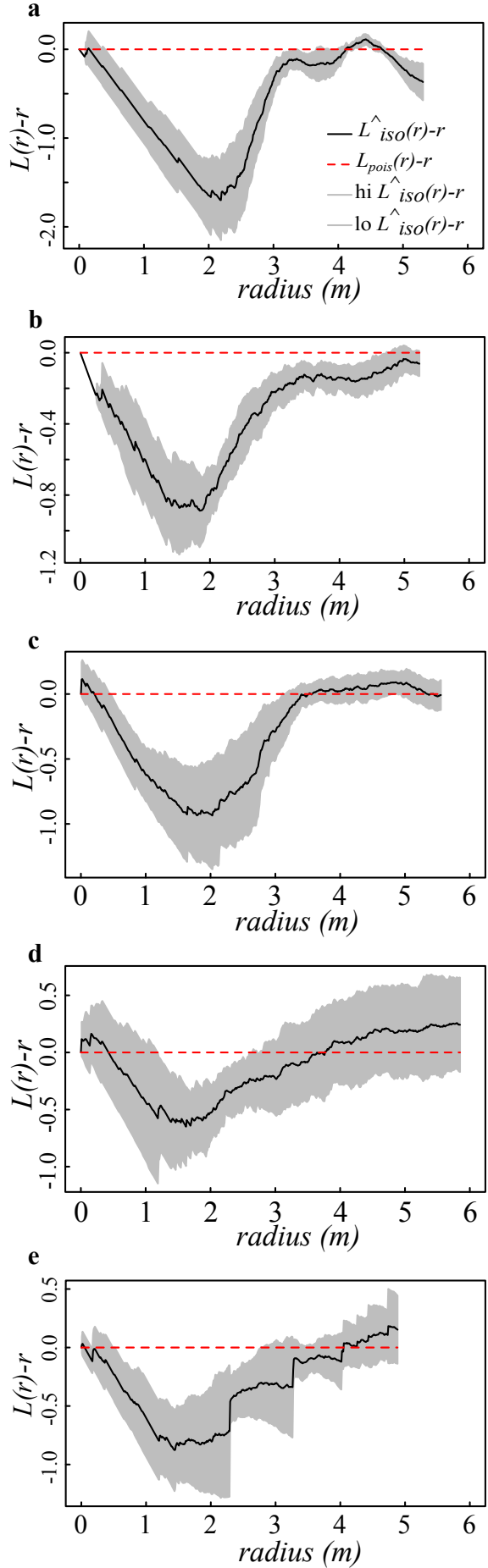

Farms from Savannah - sCAFS f
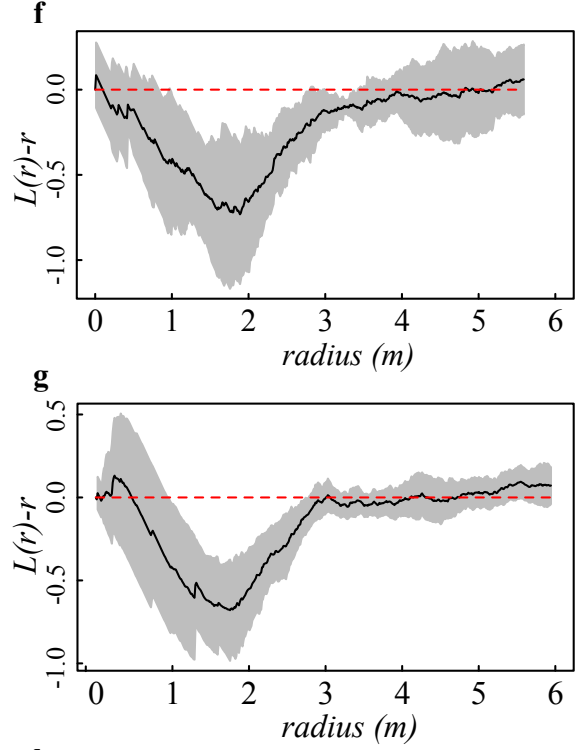

h
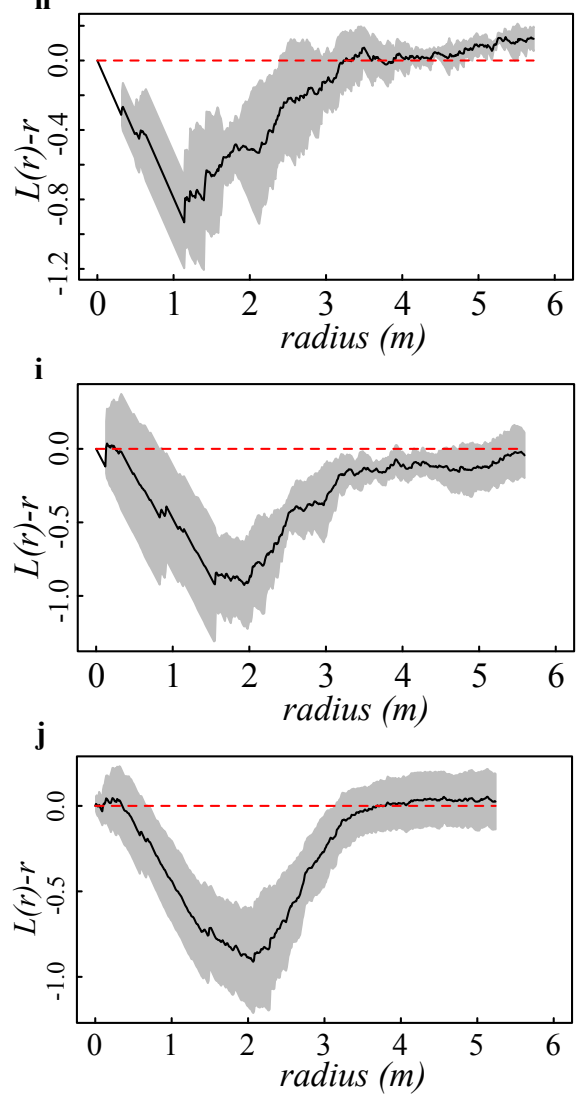

Figure 10. The centred L-function, $L i_{(r)}-r$, representation of the horizontal spatial pattern of cocoa trees in fCAFS and sCAFS farm categories. (a-e) and $(\mathbf{f}-\mathbf{j})$, respectively, for fCAFS and sCAFS, represent the following farm age groups: $\leq 10,11-20,21-40,41-60$, and $>60$ years. The dashed red line is the reference poisson distribution of Complete Spatial Randomness (CSR) for $L=0$. The black lines are the estimated value of $\mathrm{Li}$ for the distance radius. The envelopes, grey shading (i.e., $h i L_{i s o}$ and $\left.l o w L_{i s o}\right)$, are point-wise $95 \%$ confidence intervals for the true value of $\mathrm{Li}(\mathrm{r})$ based on estimated standard error. 


\subsection{Spatial Influence of Associated Trees on Replanting of Young Cocoa Trees}

The mixed poisson model postulates that there was a systematic but insignificant difference in the density of young cocoa trees between plot age groups (Table 4). The predicted density in immature fCAFS plots was about 256 trees ha $^{-1}$, and it was higher in the older plots. About 757 trees $\mathrm{ha}^{-1}$ was predicted for immature sCAFS plots; this decreased with plot age. The predicted density of young cocoa trees was about threefold more on sCAFS plots.

Irrespective of farm origin, the distance from associated trees did not significantly influence the density of young cocoa trees. The CDF test for the influence of distance from associated tree on densisty of young cocoa trees, the spatial Kolmogorov-Smirnov test, was not significant for both fCAFS $(p=0.525)$ and sCAFS $(0.223)$ (Table 4). Thus, the farm renewal practices in either planted young cocoa stems or rejuvenated old trees in the sampled plots were irrespective of the spatial distance from associated non-cocoa trees. The distance maps for the associated trees and young cocoa trees are shown in Figures $\mathrm{S} 1$ and $\mathrm{S} 2$, and the average raw residuals for the poisson point process models are summarized in Figure S3 (in the Supplementary Materials online).

Table 4. Mixed Poisson point process model statistics for young cocoa tree density across plot age groups.

\begin{tabular}{|c|c|c|c|c|c|c|c|c|c|}
\hline \multirow{2}{*}{$\begin{array}{l}\text { Farm } \\
\text { Type }\end{array}$} & \multirow{2}{*}{$\begin{array}{l}\text { Model } \\
\text { Effects }\end{array}$} & \multirow{2}{*}{ Parameters } & \multicolumn{5}{|c|}{ Plot Age Group (years) } & \multirow{2}{*}{ SD } & \multirow{2}{*}{$\begin{array}{c}\text { CDF Test } \\
D^{*}(p \text {-Value })\end{array}$} \\
\hline & & & $\leq \mathbf{1 0}$ & $11-20$ & $21-40$ & $41-60$ & $>60$ & & \\
\hline \multirow{3}{*}{ fCAFS } & Fixed & Coefficient & -3.6542 & 0.0069 & 0.3344 & 0.1753 & -0.1048 & & \multirow{3}{*}{$0.045(0.525)$} \\
\hline & \multirow{2}{*}{ Random } & Intercept & 0.03626 & 0.1741 & 0.2666 & 0.4666 & -0.1213 & 0.2338 & \\
\hline & & DAsT & -0.009 & -0.047 & -0.073 & -0.128 & 0.033 & 0.0642 & \\
\hline \multirow{3}{*}{ sCAFS } & Fixed & Coefficient & -2.580 & -0.080 & -0.853 & -1.086 & -1.1244 & & \multirow{3}{*}{$0.0365(0.223)$} \\
\hline & & Intercept & $-1.39 \times 10^{-19}$ & $-2.62 \times 10^{-19}$ & $-1.38 \times 10^{-19}$ & $-3.62 \times 10^{-19}$ & $-1.65 \times 10^{-19}$ & $3.080 \times 10^{-4}$ & \\
\hline & католо & DAsT & $-4.12 \times 10^{-22}$ & $4.06 \times 10^{-23}$ & $1.74 \times 10^{-22}$ & $-9.11 \times 10^{-23}$ & $-4.10 \times 10^{-22}$ & $2.747 \times 10^{-12}$ & \\
\hline
\end{tabular}

* The CDF test is based on the spatial Kolmogorov-Smirnov test of inhomogeneous poisson point pattern (significant coefficient have a value of $p<0.05)$. DAsT $=$ spatial covariate (distance from non-cocoa associated trees). SD $=$ Standard deviation.

\section{Discussion}

\subsection{The Structural Dynamics of Trees across Plot Age of CAFSs}

In CAFS in West and Central Africa, the recommendations on planting densities of cocoa vary between countries, the production zone, and the type of orchard (homogeneous versus agroforestry) [47]. Our results highlight variations in tree structure and prioritized ES across plot ages of similarly managed CAFSs. The high density of cocoa trees in young plots corresponds with reported values (tree density) in different landscapes in Cameroon [14]. In support of the constant cocoa density across plot age, as reported by Jagoret et al. [30] for a similar landscape, we found an insignificant reduction in density with plot age (Tables 1 and 2). A possible explanation is that field assessments may have been conducted during periods of different farm and tree management regimes. Moreover, other factors may account as well for a reduction in the density of cocoa trees. Usually in CAFSs, one or a combination of the following problems and/or management practices could account for a reduction or change in cocoa density: pest and disease attack; droughtdriven physiological stress of trees; destruction during a natural fall or deliberate felling of associated timber trees; deliberate thinning (and/or non-replacement) of cocoa trees to introduce companion shade trees of fruit, timber, non-wood and other specific uses known to farmers.

\subsection{Shade Tree Management and Basal Area Allocation}

For most plot age groups considered, the tree basal area was consistent with the generally reported or recommended value of $\leq 40 \mathrm{~m}^{2}$ ha ${ }^{-1}$. However, the basal area share of tree types was not uniform across plot ages (Figure 4). The inconsistent density and basal area of associated trees with plot age contradicts other studies that report a progressive reduction in 
associated trees with plot age in favor of cocoa trees' growth [23,29]. Our observation is in a similar cocoa production zone though restricted in spatial or landscape scope.

Amongst the several factors known to influence the type of non-cocoa trees species, either retained or planted, on CAFS is the farmer's knowledge of their potential uses [19]. Such knowledge and use change with farm management cycles, causing a shift towards prioritizing companion trees of known uses. We observed that mostly fruit trees (predominantly Citrus spp.) and other trees that provide NTFPs (Tables S2 and S3 in the Supplementary Materials) are found on the sampled plots. Moreover, their density was significantly different between plot age only on sCAFS, as shown on Table 2. It is reported that shifts in type of associated trees is a farmer' s strategy to sustain and diversify farm income, especially during the off-cocoa production season [13]. Thus, we may hypothesize that farmers are managing trees in the cocoa agroforests in their particular ways that may also depend on management challenges. As observed in certain plots, hitherto valued fruit trees (e.g., Mangifera indica) and some large associated trees are eliminated by either felling or girdling for wood fuel and/or timber. Following personal discussions with the farm managers, such trees are now perceived as soil-water and nutrient competitors for the cocoa trees.

Moreover, the density of cocoa and non-cocoa trees varied in plots within the same age group. This is echoed in the overall high variability in tree abundance between both plot age groups and the types of CAFS (fCAFS vs sCAFS), as illustrated in Figures 7 and 8. Thus, the spatial configuration of tree management in CAFS is governed by management practices that may not be easy to predict.

\subsection{Synergies and Trade-Offs between Tree Categories in CAFSs}

A number of key challenges have been previously identified to influence the application of shade tree conservation on CAFS. Shade management in CAFSs has indirect effects on farm productivity [48]: a high variability in tree density and structure is congruent with a heterogeneous light condition under canopies and areas with high light transmission through the canopy, which in turn is correlated with cocoa pest (mirids) pockets [22]. In CAFSs, adequate air circulation can be ensured by maintaining proportional basal area shares in the middle $(10-20 \mathrm{~m})$ and upper $(>20 \mathrm{~m})$ canopy strata [47]. The following management cycles have been observed for different trees categories: cocoa trees ( $0-40$ years), fruit and NTFP trees ( $0-40$ years), and timber trees (up to 80 years) [47]. Thus, although the different tree categories have variable natural life cycles, these cycles are often altered due to farm management and farmers' need for specific tree products. Our results postulate such management practices; depending on the type of CAFS (fCAFS versus SCAFS), the prominent tree categories varied at different plot ages (Figure 4). Thus, based on the reported management cycle by Sonwa et al. [47], the plots above 40 years largely comprised a second cycle of cocoa and fruits/NTFP trees, which also explains the observed low relative abundance of cocoa and fruits/NTFP trees (Figure 4). Increases in the density of non-cocoa trees, observable in CAFS, can be explained by farm renewal practices in favor of desired fruit trees.

\subsection{Reconciling Farm Intensification and the Patchy Tree Structure in CAFS}

The literature on cocoa agroforestry management has scantly reported the horizontal tree structure and, even less so, its temporal dynamics. Understanding the spatial pattern of associated non-cocoa trees is, amongst others, a simple approach to assess interactions between cocoa and shade trees [6]. We discerned a dynamic horizontal pattern of cocoa trees mostly on fCAFS-derived plots (Figure 10a-e). In Cameroon, cocoa tree planting is generally based on a recommended spacing range of 2.5 to $3.5 \mathrm{~m}$ [14]. Although farmers generally maintained this spacing (Table 4), cocoa tree configuration was irregular on a temporal scale of farm age (Figure 10).

In fCAFS plots aged below 20 years, the spatial configuration of cocoa trees correlated with a regular distribution at cumulative spatial distance of $3 \mathrm{~m}$ (Figure 10a,b). fCAFS 
plots are usually created by forest clearing and thinning. Therefore, such thinning in performed in accordance with the anticipated tree planting model for cocoa trees. Moreover, the retained trees in fCAFS are often sparsely distributed, large timber, or NTFP species for which the broad crown potentially provides a permanent shade to mature cocoa trees. This farm establishment approach, thus, gives room for a regular planting spacing for cocoa trees; meanwhile, fruit trees are planted to ensure short-term farm income and fast-growing tree crops (Musa spp.) planted for temporary shade to young cocoa trees.

In establishing CAFS on the savannah land, cocoa trees are planted in succession with previous cycles of food crop and shade tree species [11]. This may explain the random configuration of cocoa trees at cumulative distances of $\geq 3 \mathrm{~m}$ in mature and old plots of sCAFS. In such plots, farm renewal for cocoa trees is either through planting new cocoa stems as adjustment for exiting non-cocoa trees or rejuvenating new stems from older cocoa trees. In the central region of Cameroon, Jagoret et al. [29] observed that different cocoa tree architectures are used for farm rejuvenation other than tree planting, for example, cutting back old cocoa stems to enhance the development of substitute stems. A similar explanation may be the observed random distribution of cocoa trees in the immature, young, and mature sCAFS plots (Figure 10f-h). Moreover, our mixed poission point process model predicted that the density of young cocoa trees on immature CAFS plots was about threefold more on SCAFS compared with fCAFS; this is consistent with observations in the field. Based on personal communication with farm managers, a high densities of young cocoa trees are planted due to experienced low survival rate trees on sCAFS plots.

Our interpretation is that the nature and configuration of farm rejuvenation depend on farm origin, and the spatial configuration of cocoa trees was largely inconsistent with agronomic recommendations on planting spacing. We analyzed a nonuniform sample of farm types and age groups, which was biased towards plots below 11 years. However, our temporal analysis provides further information on the configuration between trees in CAFS, for which prevailing theory has been partial and focused on upper canopy trees [47].

\subsection{Shade Patterns in CAFSs}

We assessed farm rejuvenation using the proximity of young cocoa trees to non-cocoa companion and older cocoa trees. Our results show that, depending on the type of farm setup, the influence of associated shade trees on the spatial pattern of cocoa re-planting (farm rejuvenation) was not significant. However, for sCAFS, different shade trees species were dominant at different plot ages. Several models of tree spacing have been suggested for tree species in cocoa agroforests; for the companion trees, the spacing depends on species and canopy stratum [47]. However, as cocoa agroforestry plantations grow older, farm management interventions vary. Investigations about the role of associated trees within CAFS have been focusing mainly on the qualitative responses to their shade functions [23]. However, the ecosystem services provided by associated trees also depend on farm management and environment [49]. Although farmers are recommended to practice $3 \mathrm{~m}$ spacing for cocoa trees [47], such recommendations may necessitate modification in scenarios of cocoa agroforests, and the same applies to rejuvenating CAFS. Technical advice on tree management in CAFS is often incongruous to farm realities, and as oberved by [50], this consistently ranks at the top of the list of challenges faced by cocoa farmers.

Based on tree species diversity, the shade and habitat, and other non-shade ES provisions, CAFS have a recognized potential for the implementation of climate change mitigation and tree conservation mechanisms such as REDD $^{+}$[51]. Nonetheless, we observed changes in tree abundance and live biomass along the cycle of cocoa agroforests that should be considered in evaluating the ES potential of CAFSs. CAFS and other agricultural systems are increasingly subjected to erratic seasons and weather patterns, which bear existing challenges of farm adaptation such as soil nutrient and water requirements, selecting shade tree species, and the appropriate agroforest model in terms of the spatial configuration (and density) cocoa and non-cocoa trees. The negative impacts of climate change on full-sun cocoa have been widely reported. Moreover, in CAFS, there is a growing 
tendency towards reducing the density of shade trees, which may potentially impact cocoa production in most tropical countries. Thus, there is a need to develop new models of cocoa production through multi-strata agroforests [18], for instance, the appropriate spatial configuration of shade tree species and cocoa trees (densities) for different landscapes and climate conditions. However, the literature on the underlying trade-offs between the spatial configuration of cocoa trees and provisions on the density of shade trees is scarce. The model of CAFS and incentives to conserve tree species, such as farm certification, may consider the changes induced by farm rejuvenation practices on the density of associated shade trees. Our assessment of the temporal changes in tree management can provide insights on landscape history to leverage climate-related farm adaptations and incentives for tree management.

\section{Conclusions}

The potential of CAFS to sustain and provide ES is time bound and depends largely on the type and density of associated non-cocoa or shade trees. Thus, changes in the type and status of ecosystem services (ES) known to cocoa agroforestry systems (CAFS) are inevitable across farming years. Our result suggests that associated trees are managed in particular ways that depend on the farm-specific challenges and not in compliance to recommendations on spacing between trees. We report temporal changes in abundance and live biomass of trees based on farm rejuvenation (replants of young cocoa or recruits of fruits and timber species) and the density of non-cocoa companion trees. Irrespective of the type of farm establishment (fCAFS or sCAFS), the structural composition of trees is similar across farms of different ages. However, on a spatial scale, the configuration of cocoa trees changes with type of farm and plot age. By assessing the basal area changes, we provided insights on the changes in canopy strata.

Tree management is not easily predictable in cocoa agroforests as this depends on farm-specific management challenges and objectives. As observed in the sampled CAFS, the spatial configuration of cocoa trees are often far from agronomic recommendations on planting spacing $(2.5$ to $3 \mathrm{~m})$. In general, cocoa trees are planted or managed in much smaller and irregular spacing, and their spatial configuration correlates with random distribution at a cumulative distance of $\geq 3 \mathrm{~m}$; this was more obvious for fCAFS plots ( $>20$ years) and sCAFS ( $<40$ years). The density of young cocoa trees was not significantly influenced by distance from associated trees. Thus, farm rejuvenation is performed irrespective of the spatial location of non-cocoa trees, which is indicative of possible future removal of existing associated trees or changes in the type of associated tree. However, this may be conditional on intentions of continuous cocoa production in the plots or parts of the landscape. Tree conservation incentives, such as farm certification, may consider farm-specific realities and temporal variability in tree management practices in order to customize certification standards to cocoa production landscapes. For instance, incentives for tree species conservation and the price for certified cocoa could be weighted by the predominant vegetation in the landscape, and the configuration of cocoa trees based on type of CAFS (fCAFS or sCAFS). Additionally, landscapes history and dynamics could be a rational basis for assessing farm management compliance to standards, for example, in relation to tree species and spatial configuration.

We observed changes in canopy tree species and live biomass across the age of cocoa agroforests. Although the dominant live biomass was contributed by timber species, there was also a high density of fruit trees. The AGB of fruit and NTFP trees was significantly different between the age groups of sCAFS plots. Fruits trees are perceived as a means to diversify farm income sources [13]. Thus, they are potential substitutes for timber species in CAFS. Our results revealed that farm renewal through planting of young cocoa trees did not depend on distance from associated non-cocoa trees. Therefore, conditional on continuous cocoa production in the plots or parts of the landscape, which is likely to be the case, the observed farm renewal pattern is indicative of the future removal of existing associated trees and/or changes in the type of associated tree. According to the legislation 
in Cameroonian, farmers may have only usufruct rights over planted trees on farms. Such institutional policy is a potential disincentive for planting certain indigenous trees on farms [52]. For example, farmers may not be motivated to plant timber tree species that, at maturity (harvest age), do not provide economic benefits to either the current farm managers or their successors.

Concerning tree management in CAFS and cocoa landscapes, therefore, farmers are important agents that modulate the type, density, and distribution of trees. From our results, we hypothesize that the spatial configuration of cocoa trees is guided by the following management practices: (a) planting according to fixed distances, regardless of associated trees (retained or planted), as observed in fCAFS plots of $\leq 20$ years; (b) planting as an adjustment for existing trees, which results in a random configuration of cocoa tree; and (c) non-regular planting patterns and/or reliance on internal rejuvenation. Thus, other incentives, besides cocoa certification, should be derived in this regard to enhance tree management and conservation in CAFS, for instance, providing weightings on cocoa price based the model of CAFS (sCAFS or fCAFS) and spatial configuration of adaptable trees species to climatic and farm conditions.

Supplementary Materials: The following are available online at https:/ /www.mdpi.com/article/10 .3390 /su13158483/s1: Extended details on methodology and analyses; Table S1. Summary statistics for the measured variables in the sampled plots; Table S2. Diversity and use values of noncocoa/shade trees in farms of fCAFS in the study area; Table S2. Diversity and use values of non-cocoa/shade trees in farms of sCAFS in the study area; Figure S1. Tree distance map for sample farms of fCAFS type; Figure S2. Tree distance map for sample farms of sCAFS type; and Figure S3. Box plots of the raw residuals for the mixed Poisson point process models.

Author Contributions: Conceptualization, F.N.N.; methodology, F.N.N. and F.V.C.; validation, F.N.N. and F.V.C.; formal analysis, F.N.N.; investigation, F.N.N.; resources, F.V.C., D.A., and A.D.; data curation, F.N.N.; writing—original draft preparation, F.N.N.; writing—review and editing, F.N.N., D.A., A.D., and F.V.C. All authors have read and agreed to the published version of the manuscript.

Funding: This research was funded by the Special Research Fund of Ghent University and the World Agroforestry (ICRAF) Cameroon under contract number BOF DOS01W03314.

Institutional Review Board Statement: Not applicable.

Informed Consent Statement: Not applicable.

Data Availability Statement: The data presented in this study are openly available, upon request, online at https:// doi.org/10.7910/DVN/NDWBCT. The scripts for the analysis of farm structure and tree spatial pattern are accessible on https:/ / github.com/Frederick-Numbisi/CocoaTreeConfiguration.

Acknowledgments: The research was conducted under the guidance of Robert De Wulf. We are particularly grateful to the staff of ICRAF Cameroon for their support, collaboration, and hospitality during the period of field work. We also thank the cocoa farmers, especially Bidias Jean Paul and Agoume Alfred, who facilitated access to the plantations. We specially thank Elisee Tchana for his invaluable support during fieldwork. This work was supported by the Special Research Fund (BOF) of Ghent University. The field work was supported by the World Agroforestry (ICRAF) Cameroon Office.The manuscript was typeset using an open-source version of LaTeX typesetting software: Overleaf.

Conflicts of Interest: The authors declare no conflict of interest. The funders had no role in the design of the study; in the collection, analyses, or interpretation of data; in the writing of the manuscript; or in the decision to publish the results.

\section{References}

1. Bisseleua, D.H.B.; Missoup, A.D.; Vidal, S. Biodiversity conservation, ecosystem functioning, and economic incentives under cocoa agroforestry intensification. Conserv. Biol. 2009, 23, 1176-1184. [CrossRef]

2. Tscharntke, T.; Clough, Y.; Bhagwat, S.A.; Buchori, D.; Faust, H.; Hertel, D.; Hölscher, D.; Juhrbandt, J.; Kessler, M.; Perfecto, I.; et al. Multifunctional shade-tree management in tropical agroforestry landscapes-A review. J. Appl. Ecol. 2011, 48, 619-629. [CrossRef] 
3. Jacobi, J.; Andres, C.; Schneider, M.; Pillco, M.; Calizaya, P.; Rist, S. Carbon stocks, tree diversity, and the role of organic certification in different cocoa production systems in Alto Beni, Bolivia. Agrofor. Syst. 2014, 88, 1117-1132. [CrossRef]

4. Asare, R.; Afari-Sefa, V.; Osei-Owusu, Y.; Pabi, O. Cocoa agroforestry for increasing forest connectivity in a fragmented landscape in Ghana. Agrofor. Syst. 2014, 88, 1143-1156. [CrossRef]

5. Vaast, P.; Somarriba, E. Trade-offs between crop intensification and ecosystem services: The role of agroforestry in cocoa cultivation. Agrofor. Syst. 2014, 88, 947-956. [CrossRef]

6. Somarriba, E.; Orozco-Aguilar, L.; Cerda, R.; López-Sampson, A. Analysis and design of the shade canopy of cocoa-based agroforestry systems. In Achieving Sustainable Cultivation of Cocoa; Burleigh Dodds Science Publishing: Cambridge, UK, 2018; pp. 469-499. [CrossRef]

7. Tollens, E. Potential Impacts of Agriculture Development on the Forest Cover in the Congo Basin; The World Bank: Washintgon, DC, USA, 2010.

8. Ruf, F.; Schroth, G.; Doffangui, K. Climate change, cocoa migrations and deforestation in West Africa: What does the past tell us about the future? Sustain. Sci. 2015, 10, 101-111. [CrossRef]

9. Ordway, E.M.; Asner, G.P.; Lambin, E.F. Deforestation risk due to commodity crop expansion in sub-Saharan Africa Deforestation risk due to commodity crop expansion in sub- Saharan Africa. Environ. Res. Lett. 2017, 12. [CrossRef]

10. FAOSTAT. Crops. FAO, Data. 2019. Available online: http://www.fao.org/faostat/en/\#data/QCL (accessed on 5 November 2019)

11. Jagoret, P.; Michel-Dounias, I.; Snoeck, D.; Ngnogué, H.T.; Malézieux, E. Afforestation of savannah with cocoa agroforestry systems: A small-farmer innovation in central Cameroon. Agrofor. Syst. 2012, 86, 493-504. [CrossRef]

12. Dumont, S.E.; Gnahoua, G.M.; Ohouo, L.; Sinclair, F.L.; Vaast, P. Farmers in Côte d'Ivoire value integrating tree diversity in cocoa for the provision of ecosystem services. Agrofor. Syst. 2014, 88, 1047-1066. [CrossRef]

13. Gyau, A.; Smoot, K.; Diby, L.; Kouame, C. Drivers of tree presence and densities: The case of cocoa agroforestry systems in the Soubre region of Republic of Côte d'Ivoire. Agrofor. Syst. 2015, 89, 149-161. [CrossRef]

14. Sonwa, D.J.; Weise, S.F.; Nkongmeneck, B.A.; Tchatat, M.; Janssens, M.J.J. Structure and composition of cocoa agroforests in the humid forest zone of Southern Cameroon. Agrofor. Syst. 2016, 91, 451-470. [CrossRef]

15. Gockowski, J.; Sonwa, D. Cocoa intensification scenarios and their predicted impact on $\mathrm{CO}_{2}$ emissions, biodiversity conservation, and rural livelihoods in the Guinea rain forest of West Africa. Environ. Manag. 2011, 48, 307-321. [CrossRef]

16. Pedelahore, P. Farmers accumulation strategies and agroforestry systems intensification: The example of cocoa in the central region of Cameroon over the 1910-2010 period. Agrofor. Syst. 2014, 88, 1157-1166. [CrossRef]

17. Saj, S.; Durot, C.; Mvondo Sakouma, K.; Tayo Gamo, K.; Avana-Tientcheu, M.L. Contribution of associated trees to long-term species conservation, carbon storage and sustainability: A functional analysis of tree communities in cacao plantations of Central Cameroon. Int. J. Agric. Sustain. 2017, 5903, 1-21. [CrossRef]

18. Schroth, G.; Läderach, P.; Martinez-valle, A.I.; Bunn, C.; Jassogne, L. Vulnerability to climate change of cocoa in West Africa: Patterns, opportunities and limits to adaptation. Sci. Total Environ. J. 2016, 556, 231-241. [CrossRef] [PubMed]

19. Laird, S.A.; Awung, G.L.; Lysinge, R.J. Cocoa farms in the Mount Cameroon region: Biological and cultural diversity in local livelihoods. Biodivers. Conserv. 2007, 16, 2401-2427. [CrossRef]

20. Gyau, A.; Smoot, K.; Kouame, C.; Diby, L.; Kahia, J.; Ofori, D. Farmer attitudes and intentions towards trees in cocoa (Theobroma cacao L.) farms in Côte d'Ivoire. Agrofor. Syst. 2014, 88, 1035-1045. [CrossRef]

21. Bos, M.M.; Steffan-Dewenter, I.; Tscharntke, T. Shade tree management affects fruit abortion, insect pests and pathogens of cacao. Agric. Ecosyst. Environ. 2007, 120, 201-205. [CrossRef]

22. Babin, R.; Anikwe, J.C.; Dibog, L.; Lumaret, J.P. Effects of cocoa tree phenology and canopy microclimate on the performance of the mirid bug Sahlbergella singularis. Entomol. Exp. Et Appl. 2011, 141, 25-34. [CrossRef]

23. Saj, S.; Jagoret, P.; Todem Ngogue, H. Carbon storage and density dynamics of associated trees in three contrasting Theobroma cacao agroforests of Central Cameroon. Agrofor. Syst. 2013, 87, 1309-1320. [CrossRef]

24. Gockowski, J.; Afari-Sefa, V.; Sarpong, D.B.; Osei-Asare, Y.B.; Agyeman, N.F. Improving the productivity and income of Ghanaian cocoa farmers while maintaining environmental services: What role for certification? Int. J. Agric. Sustain. 2013, 11, 331-346. [CrossRef]

25. Richard, A.; Ræbild, A. Tree diversity and canopy cover in cocoa systems in Ghana. New For. 2016, 47, 287-302. [CrossRef]

26. Asare, R.; Asare, R.A.; Asante, W.A.; Markussen, B.; Ræbild, A. Influences of Shading and Fertilization on on-Farm Yields of Cocoa in Ghana. Exp. Agric. 2016, 53, 416-431. [CrossRef]

27. Mbile, P.; Ngaunkam, P.; Besingi, M.; Nfoumou, C.; Degrande, A.; Tsobeng, A.; Sado, T.; Menimo, T. Farmer management of cocoa agroforests in Cameroon: Impacts of decision scenarios on structure and biodiversity of indigenous tree species. Biodiversity 2009, 10, 12-19. [CrossRef]

28. Jagoret, P.; Kwesseu, J.; Messie, C.; Michel-Dounias, I.; Malézieux, E. Farmers' assessment of the use value of agrobiodiversity in complex cocoa agroforestry systems in central Cameroon. Agrofor. Syst. 2014, 88, 983-1000. [CrossRef]

29. Jagoret, P.; Snoeck, D.; Bouambi, E.; Ngnogue, H.T.; Nyassé, S.; Saj, S. Rehabilitation practices that shape cocoa agroforestry systems in Central Cameroon: Key management strategies for long-term exploitation. Agrofor. Syst. 2017, 92, 1185-1199. [CrossRef] 
30. Jagoret, P.; Michel-Dounias, I.; Malézieux, E. Long-term dynamics of cocoa agroforests: A case study in central Cameroon. Agrofor. Syst. 2011, 81, 267-278. [CrossRef]

31. Batcheler, C.L.; Craib, D.G. A variable area plot method of assessment of forest condition and trend. N. Z. J. Ecol. 1985, 8, 83-95.

32. Allen, R.B. A Permanent Plot Method for Monitoring Changes in Indigenous Forests: A Field Manual; Technical Report January 1993; Manaaki Whenua-Landcare Research: Christchurch, New Zealand, 1993.

33. Woo, S.Y.; Thai, H.T.; Park, P.S. Stand structure and natural regeneration of degraded forestland in the northern mountainous region of Vietnam. Landsc. Ecol. Eng. 2011, 7, 251-261. [CrossRef]

34. Deheuvels, O.; Rousseau, G.X.; Soto Quiroga, G.; Decker Franco, M.; Cerda, R.; Vílchez Mendoza, S.J.; Somarriba, E. Biodiversity is affected by changes in management intensity of cocoa-based agroforests. Agrofor. Syst. 2014, 88, 1081-1099. [CrossRef]

35. Maleki, K.; Kiviste, A. Effect of sample plot size and shape on estimates of structural indices: A case study in mature silver birch (Betula pendula Roth) dominating stand in Järvselja. For. Stud. 2015, 63, 130-150. [CrossRef]

36. Cerda, R.; Deheuvels, O.; Calvache, D.; Niehaus, L.; Saenz, Y.; Kent, J.; Vilchez, S.; Villota, A.; Martinez, C.; Somarriba, E. Contribution of cocoa agroforestry systems to family income and domestic consumption: Looking toward intensification. Agrofor. Syst. 2014, 88, 957-981. [CrossRef]

37. Réjou-Méchain, M.; Tanguy, A.; Piponiot, C.; Chave, J.; Hérault, B. biomass: An r package for estimating above-ground biomass and its uncertainty in tropical forests. Methods Ecol. Evol. 2017, 8, 1163-1167. [CrossRef]

38. Chave, J.; Réjou-Méchain, M.; Búrquez, A.; Chidumayo, E.; Colgan, M.S.; Delitti, W.B.; Duque, A.; Eid, T.; Fearnside, P.M.; Goodman, R.C.; et al. Improved allometric models to estimate the aboveground biomass of tropical trees. Glob. Chang. Biol. 2014, 20, 3177-3190. [CrossRef] [PubMed]

39. Zanne, A.; Lopez-Gonzalez, G.; Coomes, D.; Ilic, J.; Jansen, S.; Lewis, S.; Miller, R.B.; Swenson, N.G.; Wiemann, M.C.; Chave, J. Global Wood Density Database. Dryad Dataset 2009. [CrossRef]

40. Lutz, J.A.; Furniss, T.J.; Johnson, D.J.; Davies, S.J.; Allen, D.; Alonso, A.; Anderson-Teixeira, K.J.; Andrade, A.; Baltzer, J.; Becker, K.M.; et al. Global importance of large-diameter trees. Glob. Ecol. Biogeogr. 2018, 27, 849-864. [CrossRef]

41. Turner, R. Point patterns of forest fire locations. Environ. Ecol. Stat. 2009, 16, 197-223. [CrossRef]

42. Ngo Bieng, M.A.; Ginisty, C.; Goreaud, F. Point process models for mixed sessile forest stands. Ann. For. Sci. 2011, 68, 267-274. [CrossRef]

43. Fonton, N.H.; Atindogbe, G.; Hounkonnou, N.M.; Dohou, R.O. Plot size for modelling the spatial structure of sudanian woodland trees. Ann. For. Sci. 2011, 68, 1315-1321. [CrossRef]

44. Ngo Bieng, M.A.; Gidoin, C.; Avelino, J.; Cilas, C.; Deheuvels, O.; Wery, J. Diversity and spatial clustering of shade trees affect cacao yield and pathogen pressure in Costa Rican agroforests. Basic Appl. Ecol. 2013, 14, 329-336. [CrossRef]

45. Baddeley, A.; Turner, R.; Rubak, E. Analysing replicated point patterns in spatstat. Cran Vignettes 2015, 35, 38

46. Ripley, B. Modelling Spatial Patterns. J. R. Stat. Soc. Ser. B (Methodol.) 1977, 39, 172-212. [CrossRef]

47. Sonwa, D.J.; Weise, S.F.; Schroth, G.; Janssens, M.J.J.; Shapiro, H.Y. Structure of cocoa farming systems in West and Central Africa: A review. Agrofor. Syst. 2018. [CrossRef]

48. Daghela Bisseleua, H.B.; Fotio, D.; Yede.; Missoup, A.D.; Vidal, S. Shade Tree Diversity, Cocoa Pest Damage, Yield Compensating Inputs and Farmers' Net Returns in West Africa. PLoS ONE 2013, 8. [CrossRef]

49. Wood, S.A.; Karp, D.S.; Declerck, F.; Kremen, C.; Naeem, S.; Palm, C.A. Functional traits in agriculture: Agrobiodiversity and ecosystem services. Trends Ecol. Evol. 2015, 30, 531-539. [CrossRef] [PubMed]

50. Alemagi, D.; Duguma, L.; Minang, P.A.; Nkeumoe, F.; Feudjio, M.; Tchoundjeu, Z. Intensification of cocoa agroforestry systems as a REDD+ strategy in Cameroon: Hurdles, motivations, and challenges. Int. J. Agric. Sustain. 2015, 13, 187-203. [CrossRef]

51. Bernard, F.; Minang, P.A. Community forestry and REDD + in Cameroon: What future? Ecol. Soc. 2019, 24, 14 [CrossRef]

52. Foundjem-Tita, D.; D'Haese, M.; Speelman, S.; Degrande, A.; Gyau, A.; Van Damme, P.; Tchoundjeu, Z.; Van Huylenbroeck, G. Would strictly enforced forestry regulations affect farmers' stated intentions to plant indigenous fruits trees? Insights from Cameroon. Food Policy 2014, 49, 95-106. [CrossRef] 